\title{
WestVirginiaUniversity
}

THE RESEARCH REPOSITORY @ WVU

Graduate Theses, Dissertations, and Problem Reports

2006

\section{Suggestibility in an adolescent and young adult sample: Age and individual differences}

Rebecca G. Ryan

West Virginia University

Follow this and additional works at: https://researchrepository.wvu.edu/etd

\section{Recommended Citation}

Ryan, Rebecca G., "Suggestibility in an adolescent and young adult sample: Age and individual differences" (2006). Graduate Theses, Dissertations, and Problem Reports. 4263.

https://researchrepository.wvu.edu/etd/4263

This Dissertation is protected by copyright and/or related rights. It has been brought to you by the The Research Repository @ WVU with permission from the rights-holder(s). You are free to use this Dissertation in any way that is permitted by the copyright and related rights legislation that applies to your use. For other uses you must obtain permission from the rights-holder(s) directly, unless additional rights are indicated by a Creative Commons license in the record and/ or on the work itself. This Dissertation has been accepted for inclusion in WVU Graduate Theses, Dissertations, and Problem Reports collection by an authorized administrator of The Research Repository @ WVU.

For more information, please contact researchrepository@mail.wvu.edu. 
Suggestibility in an Adolescent and Young Adult Sample:

Age and Individual Differences

Rebecca G. Ryan

Dissertation submitted to the Eberly College of Arts and Sciences at West Virginia University in partial fulfillment of the requirements for the degree of

Doctor of Philosophy

in

Life-Span Developmental Psychology

Matthew H. Scullin, Ph.D., Chair

Steven A. Branstetter, Ph.D.

James J. Nolan, III, Ph.D.

B. Kent Parker, Ph.D.

Julie H. Patrick, Ph.D.

Department of Psychology

Morgantown, West Virginia 2006

Keywords: Suggestibility, Individual Differences, Adolescents

Copyright 2006 Rebecca G. Ryan 


\section{ABSTRACT \\ Suggestibility in an Adolescent and Young Adult Sample: \\ Age and Individual Differences}

\section{Rebecca G. Ryan}

The current study was an investigation of age differences in interrogative suggestibility and its components; Yield, Shift, and Total Suggestibility. Adolescents and young adults were compared on these measures and it was found that young adults Yield significantly less than adolescents and that Total Suggestibility was lower for the young adults compared to the adolescents. Young adults were also found to display significantly higher levels of both memory and source monitoring ability. Regressions were conducted with individual difference factors associated with Yield, Shift, and Total Suggestibility. For Yield, memory was found to be a unique contributor. For Shift and Total Suggestibility memory, source monitoring, and social desirability were found to be unique contributors, with social desirability contributing over age, memory, and source monitoring. The findings of the current study are applicable both to research in the area of interrogative suggestibility and within the legal setting. 


\section{Dedication}

This work is dedicated to my mother, who always provided loving support and understanding. 


\section{Acknowledgements}

I would like to acknowledge the mentorship and assistance of Drs. Matthew Scullin, Julie Patrick, Jennifer Margrett, Jim Nolan, Kent Parker, Steven Branstetter, Stan Cohen, and Daniel McNeil. I would also like to acknowledge the hard work of the dedicated undergraduate research assistants in the Scullin Lab; they were invaluable in the completion of my work. I am also very appreciative of the monetary assistance provided to me by the department, college, and alumni. Finally, I would like to thank my family, friends, and Jason; whose love and support got me through it all. 
Table of Contents

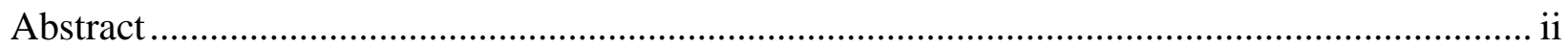

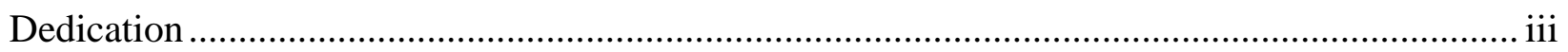

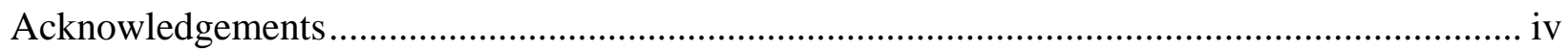

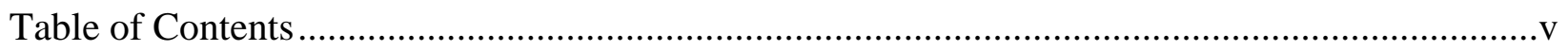

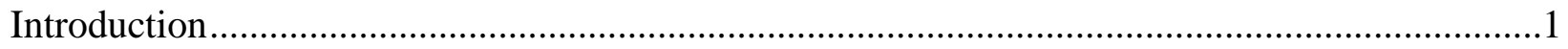

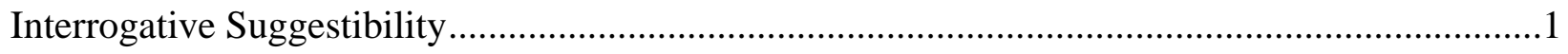

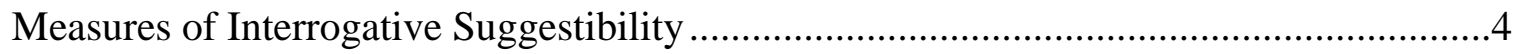

Developmental Trends in Adult Interrogative Suggestibility ......................................5

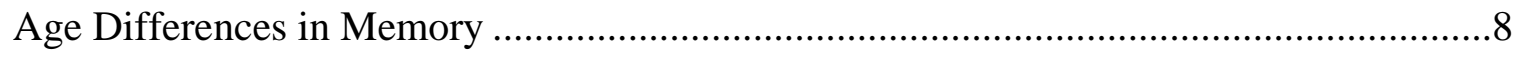

Individual Differences in Interrogative Suggestibility ...........................................

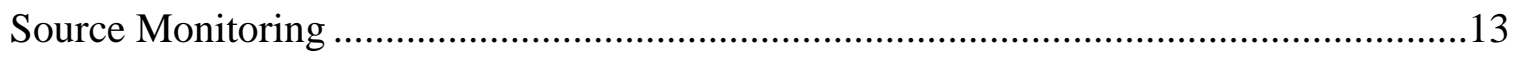

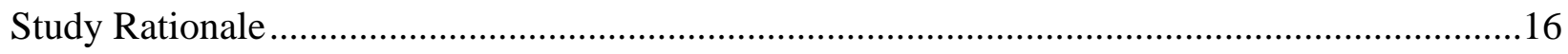

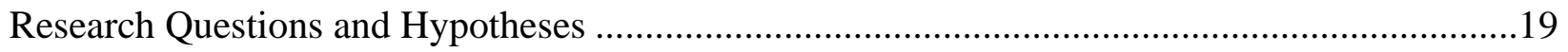

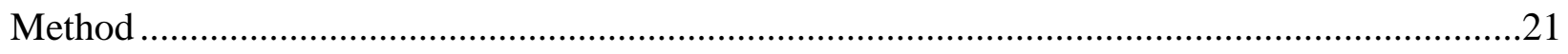

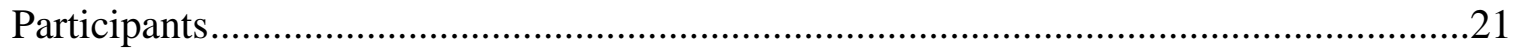

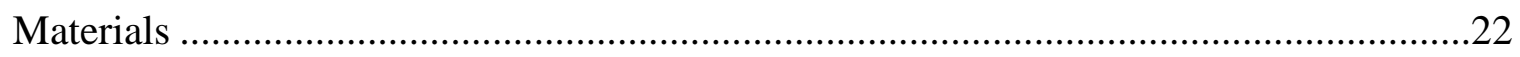

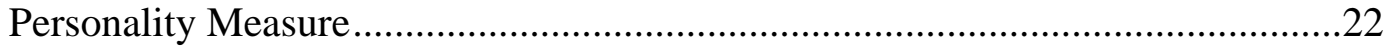

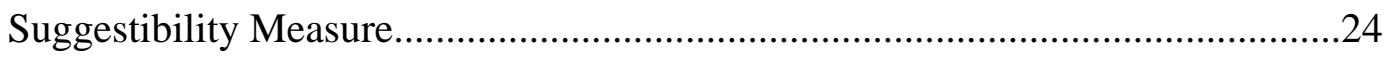

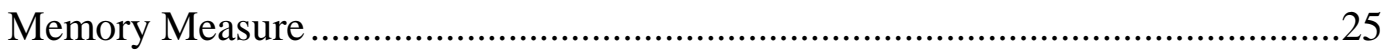

Source Monitoring Measure ...................................................................26

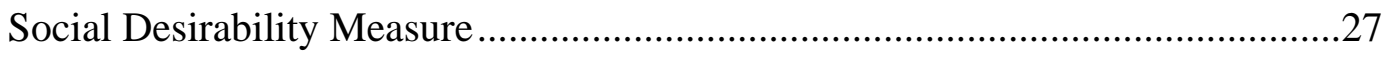

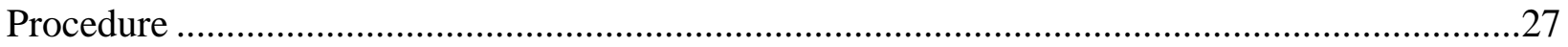


Results.

Descriptive Results .28

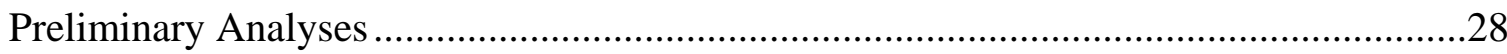

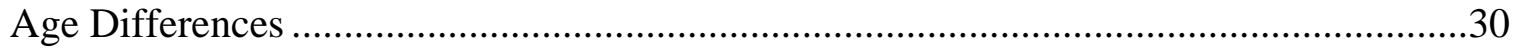

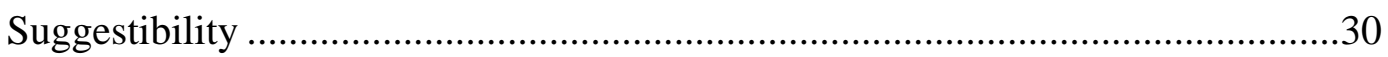

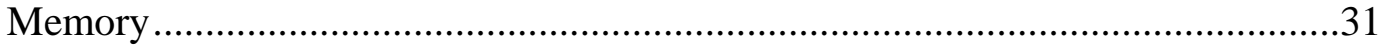

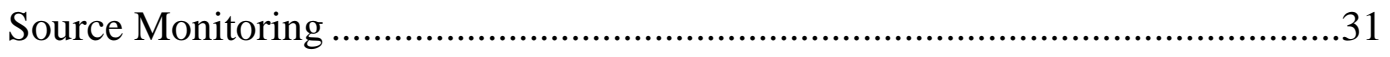

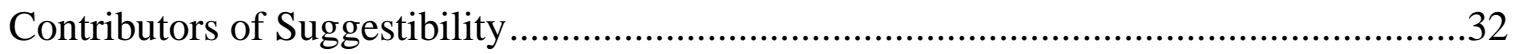

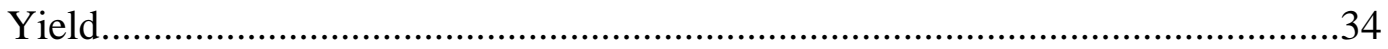

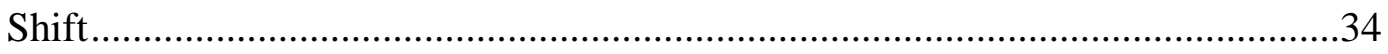

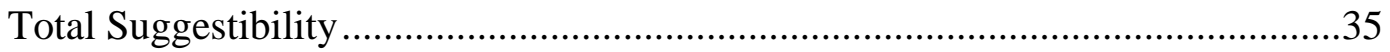

Additional Individual Differences Analyses.........................................................37

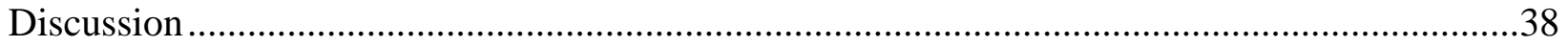

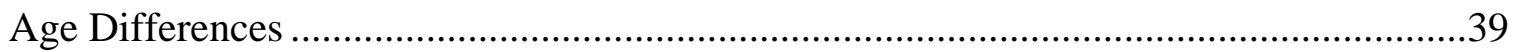

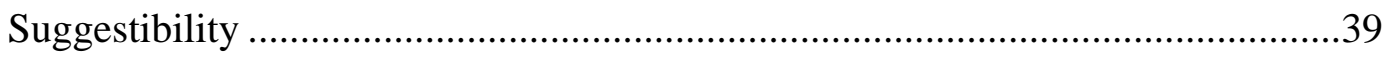

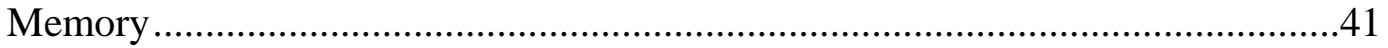

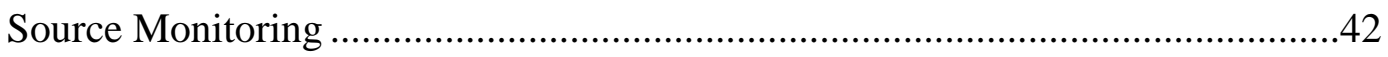

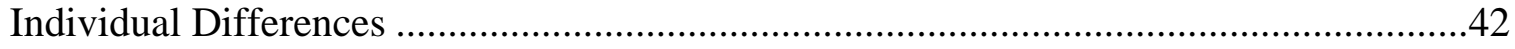

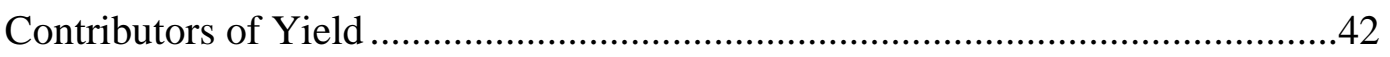

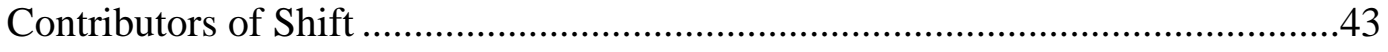

Contributors of Total Suggestibility ............................................................43 
Additional Individual Differences Analyses......................................................................44

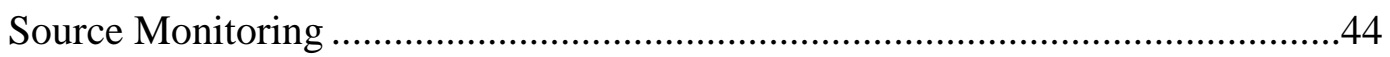

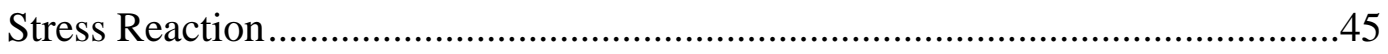

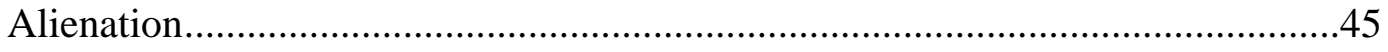

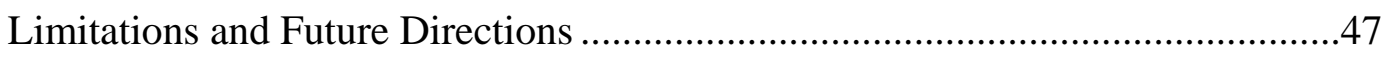

Conclusions and Applications.............................................................................48

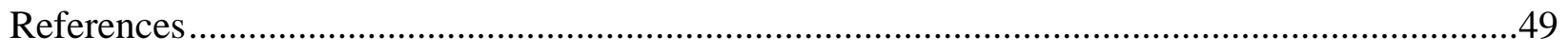

Tables

Table 1: Constructs and Measures ..................................................................................54

Table 2: Entire Sample: Descriptive Statistics...................................................................55

Table 3: Descriptive Statistics and Summary of Analyses of Variance .............................56

Table 4: Correlations among Suggestibility and Contributor Variables..............................58

Table 5: Correlations among Suggestibility and Contributor Variables by Age................59

Table 6: Summary of Hierarchical Regression Analyses Yield ..........................................60

Table 7: Summary of Hierarchical Regression Analyses Shift .........................................62

Table 8: Summary of Hierarchical Regression Analyses Total Suggestibility..................64 Appendices

Appendix A: Personality Inventory ...........................................................................66

Appendix B: Demographics Questionnaire .................................................................71

Appendix C: Video Suggestibility Scale for Adults Interview...........................................73

Appendix D: Source Monitoring Measure......................................................................78

Appendix E: Unlikely Virtues Scale of the MPQ-BF......................................................84 
Suggestibility in an Adolescent and Young Adult Sample: Age and Individual Differences

The current study explored both age differences in suggestibility and individual difference factors potentially related to suggestibility. This study investigated the nature of suggestibility within both an adolescent and young adult sample so that potential differences in suggestibility between these two groups could be explored. The individual difference factors of personality, social desirability, memory, and source monitoring ability and their relation to suggestibility were explored and the potentially differential influence these factors have on suggestibility was investigated. The type of suggestibility in this study is referred to as interrogative suggestibility.

\section{Interrogative Suggestibility}

In the field of eyewitness memory research, suggestibility refers a person's tendency to accept suggestive influences. Interrogative suggestibility is a subfield of this research that deals with suggestibility occurring during the process of investigative interviews. There are two approaches associated with research pertaining to interrogative suggestibility: the experimental approach and the individual differences approach (Schooler \& Loftus, 1986). The experimental approach is most strongly associated with the work of Loftus and her colleagues, who investigated how and under what conditions suggestive interview techniques impact eyewitness memory (Loftus, Miller, \& Burns, 1978).

The individual differences approach is associated with Gudjonsson and tends to focus on determining how individuals use various coping strategies in order to manage uncertainty caused by suggestive interview techniques (Gudjonsson, 2003). This process of coping with uncertainty is influenced by at least two factors that explain why individuals are differentially impacted by leading questions and interrogative pressure. One of these factors is referred to as Yield and is 
assessed by summing all instances of responding affirmatively to misleading suggestive questions. Yield is believed to reflect a cognitive component of suggestibility. Responding affirmatively to a misleading question might occur because the individual cannot recall the event in question. This memory deficit leads the individual to accept the misinformation contained in the suggestive question.

The other factor is referred to as Shift and is assessed by summing instances of changes in a person's response to the same set of questions after the presentation of negative feedback. Shift is believed to reflect a social component of suggestibility. After being asked a series of both misleading and nonmisleading questions, the individual is told that they answered some of the questions incorrectly and so they are going to be asked the questions again. A change in response is believed to be due to perceived social pressure. Both an individual's predisposition to acquiesce to suggestive questions and the characteristics of the interview situation that cause a person to be suggestible contribute to interrogative suggestibility (Gudjonsson, 2003), the focus of the current study.

Though Yield is considered to be a more cognitive component of suggestibility and Shift is considered to be a more social component of suggestibility, these two constructs are influenced by both cognitive and social factors. The initial questioning of the individual, during which she or he might respond affirmatively to inaccurate leading questions (Yield), is considered to be an assessment of that individual's memory for the event in question, thus their cognitive memory ability is put to the test. However, the interview is a social interaction as well and social influences, such as demeanor and reactions, may impact the responses the individual provides. The second round of questioning, during which the individual might change their response to a question (Shift), is considered to be an assessment of the individuals reaction to 
social pressure in the form of the negative feedback that is presented immediately after the initial round of questioning, thus Shift is considered to be the result of social influence. However, the second round of questioning also requires the individual to recall information and utilize their cognitive memory skills once again in order to determine what they believe to be the correct answer. The discussions of Yield and Shift that follow will accept and use the traditional conception of these constructs as being more cognitive and social respectively. Though it is understood that both constructs are not purely determined by either cognitive or social factors, Gudjonsson has asserted that they are more influenced by one factor than another.

Both experimental misleading interview protocols and structured measures for assessing individual differences in interrogative suggestibility share some similar techniques. Both entail posing inaccurate leading questions as a way of assessing the suggestibility of an individual. This involves asking participants close-ended questions which contain inaccurate information about an event they experienced. In the individual differences approach, acquiescence (responding "yes") to such questions is considered a Yield (Gudjonsson, 2003). For example, an inaccurate leading question might ask "Did the man have on a watch?" when in fact the man in question did not have on a watch. There are also accurate leading questions such as the same question when the man in the target event was wearing a watch. These questions present information about the event in question that has not been previously revealed by the interviewee as opposed to asking questions that request the interviewee to recall everything that the person in question was wearing or everything about her or his appearance.

Another interview technique used, primarily in the individual differences approach, for assessing suggestibility entails posing questions to participants, followed by negative feedback or social pressure that is intended to encourage them to change their original responses to the 
questions. Changes in responses after such feedback are considered a Shift (Gudjonsson, 2003). For example, asking a series of questions pertaining to a previously experienced event followed by a statement such as "Some of the answers you gave were incorrect, let's go through them again" and subsequently asking the series of questions again would also provide evidence as to how suggestible an individual is. The structured measures for assessing individual differences in interrogative suggestibility assess suggestibility by measuring Yields and Shifts.

\section{Measures of Interrogative Suggestibility}

Since the mid-1980s, researchers have developed standardized interrogative suggestibility measures, including the Gudjonsson Suggestibility Scale (GSS); (Gudjonsson, 1984) and the Video Suggestibility Scale for Children (Scullin \& Ceci, 2001). These two measures of suggestibility both assess individual differences in tendencies to Yield and Shift. The oldest and most widely used measures of suggestibility are the Gudjonsson Suggestibility Scales. These scales assess interrogative suggestibility by presenting a target event (playing an audiotape of a narrative) followed by a series of recall tasks. This process entails an immediate free recall session as well as a delayed free recall session that takes place after 50 minutes. After the delayed free recall, participants are given an interview which contains both inaccurate leading and accurate leading questions. There are a total of 20 questions, 15 of which are leading and 5 of which are nonleading.

The interview component of this scale involves asking the series of questions once and acquiescence to inaccurate leading questions are counted as Yields. After this negative feedback is presented it is followed by the series of questions being asked again. Changes in response are counted as Shifts. During this phase Yields are counted again and referred to as Yield 2. In sum these scales measure immediate recall, delayed recall, Yield 1, Yield 2, Shift, Total 
Suggestibility (the sum of Yield 1 and Shift), and confabulation. The confabulation component is rarely used by researchers and refers to when the individual changes a major aspect of the target event (distortion) or adds a new aspect to the event (fabrication) during free recall (Gudjonsson, 2003).

The Video Suggestibility Scale for Adults (VSSA) is a new measure of suggestibility which is currently being developed by Bonner and Scullin. This assessment is intended to provide a method of assessing suggestibility using procedures more congruent to real-world forensic situations. The VSSA entails showing participants a video in which a perpetrator videotapes himself committing two crimes with different accomplices. One of the crimes involves the videotaper and his accomplice stealing a woman's car and the other crime involves the same videotaper and two different accomplices robbing a neighbor's home. These videos were made by Bonner for the scale. After viewing the videos, the interview consists of a free recall portion followed by a series of probe questions which contain both suggestive and nonsuggestive questions. The free recall portion entails asking the interviewees to report everything that they can remember about the crimes. The questioning portion entails asking 111 questions, including 50 inaccurate leading questions and 61 accurate leading questions. The free recall portion of the VSSA allows for the assessment of the interviewee's general memory ability. The questioning portion of the interview allows for the calculation of Yield, Shift, and Total Suggestibility in accordance with the previously described methods.

Developmental Trends in Adolescent and Young Adult Interrogative Suggestibility Research pertaining to age differences in suggestibility has commonly shown younger children to be more suggestible than older children and children in general to be more suggestible than adults (Cassel \& Bjorklund, 1995). Although suggestibility in children has been 
widely examined with both the experimental and individual differences approach (Bruck \& Melnyk, 2004; Ceci \& Bruck, 1993), there is a clear need for research that examines the nature of suggestibility and the individual differences related to suggestibility within adolescent populations (Bruck \& Ceci, 1999; Singh \& Gudjonsson, 1992).

The majority of the studies that have used adolescent participants have assessed a special population, namely delinquents. One such study conducted by Richardson, Gudjonsson, and Kelly (1995) compared the performance of adolescent offenders ( $M$ age $=15$ years $)$ to adult offenders ( $M$ age $=30$ years $)$ on the GSS. These researchers found that the adolescents were more suggestible than the adults as evidenced by a higher number of Shifts (changing their responses after feedback) but that the adolescents were no more suggestible than the adults as evidenced by a similar number of Yields (acquiescing to inaccurate leading questions). Based on this finding the researchers reported that adolescents may be more vulnerable to the effects of interrogative pressure than adults.

The adolescent offenders in Richardson and Kelly's (1995) study were residents of a facility for young individuals with serious behavioral difficulties and the majority of the participants also shared a background of unstable family situations. The behavioral difficulties were often associated with problems at school, antisocial behavior, problematic social relationships, and criminal offences. Delinquent adolescents are not only distinct from nondelinquent populations due to these characteristics of their behavior and experiences, but previous research has also shown that delinquents are more suggestible than nondelinquents, as evidenced by higher numbers of Shifts and greater increase in Yield scores from Yield 1 to Yield 2 (Richardson, Gudjonsson, \& Kelly, 1995). Thus not only are there few studies which assess suggestibility in nondelinquent adolescents, the studies that have included delinquent adolescents 
could potentially provide findings which are not representative of the general population of adolescents.

The effects of posing inaccurate leading questions to interviewees have been studied with various age groups. Children under 12 have been found to be especially susceptible to memory impairment and source confusions, whereas it appears that after age 12, susceptibility to inaccurate leading questions reaches levels that are not significantly different from those of adults (Gudjonsson, 2003). Again, the consensus has been based upon studies which have used primarily institutionalized delinquents. Even though no differences were seen with this population in regard to Yielding to inaccurate leading questions, differences were still evident when comparing the number of times the adolescents displayed Shifts in their responses. This has led researchers to conclude that adolescents, compared to adults, are less able to deal with the social pressure placed on them as a result of negative feedback (Gudjonsson, 2003).

An unpublished study conducted by Redlich was cited in Gudjonsson's (2003) review of the literature pertaining to suggestibility and age differences. As reported by Gudjonsson, no significant differences in suggestibility were found between the age groups of 12- to 13-, 15- to 16-, and 18- to 26-year-olds. In Redlich's study, suggestibility was assessed with the Gudjonsson Suggestibility Scale for the purpose of investigating whether suggestibility was associated with a tendency to accept a false accusation of guilt. Although Redlich did not find age differences in suggestibility when examining adolescents and young adults, this study may have been conducted with a measure of suggestibility which is not sensitive enough to detect such age differences. There is a need for both research which utilizes more sensitive and ecologicallyvalid measures of interrogative suggestibility and replications of studies which include this understudied age group. Within this age group there is also the need for the study of individual 
differences related to suggestibility. As will be reviewed, previous studies have revealed that specific individual difference factors are more closely related to suggestibility at various ages.

\section{Age Differences in Memory}

The current study explored age differences in suggestibility and memory abilities between adolescents and young adults. This is believed to be an important issue as there is a lack of research which has compared adolescents to young adults on levels of interrogative suggestibility and various measures of memory for forensically-relevant information. Although these two age groups are not highly disparate, some developmental differences have been displayed in studies comparing these two age groups and age groups with little discrepancy, on other measures of memory ability.

In one such study, Parente (2001) compared seventh and eighth graders to college students on a measure of explicit memory. Explicit memory pertains to conscious recollections and may be tested with measures such as free recall and cued recall of previously-presented stimuli. Parente measured explicit memory by having her participants read a list of words and recall as many as they could; the total number of correctly recalled words served as the data on this measure. The college students' explicit memory scores were significantly higher than the junior high students' explicit memory scores.

Adams (1991) found significant differences between age groups with little discrepancy in age when she compared levels of accurate recall pertaining to memory for text. This researcher used a sample which included four age groups and assessed memory with the use of a narrative which the participants were asked read. After a short filler task, participants were asked to write down as much as they could remember. The recollections were coded for the total number of accurate complete idea units (the expression of a single idea, action, or state) and these scores 
were compared between the age groups. Adams referred to the sample as young adolescents (1215 years), older adolescents (16-19 years), middle-aged adults (39-56 years), and older adults (60-78 years) and found that the older adolescents and the middle-aged adults had significantly higher mean scores than the younger adolescents and the older adults. Specifically, pertaining to the expectation of the current study for finding differences between two groups which do not differ greatly in age, Adams found the 16- to 19-year-old group displayed a significantly higher level of recall compared to the 12- to 15-year-old group.

In a study that focused on the development of memory abilities during adolescence, Ryan (1990) compared age groups across adolescence, namely, 12- to 14-year-olds, 14- to 16-yearolds, and 16- to 19-year-olds. Ryan mentioned the need for research in the area of memory efficiency which compares such close age ranges as, most studies "focus on the extremes of the age continuum" and studies which investigate age differences in memory "rarely include normal subjects between ages of 12 and 18" (p.193). Ryan found that the 16- to 19-year-olds performed significantly better on a measure of short term memory (word list recall) and a forward digit span task compared to the 12- to 14-year-olds. Although these age differences in memory ability were not found with measures of long term memory as would be assessed by the current study, Ryan's work nonetheless points out the importance of exploring age differences within small increments of age.

Individual Differences in Adolescent and Young Adult Interrogative Suggestibility Previous studies have investigated the relation between suggestibility and numerous variables, some of which include intelligence, personality factors, memory skill, gender, anxiety, impulsivity, social desirability, assertiveness, self-esteem, and anger (Gudjonsson, 2003). These individual differences studies allow for a greater understanding of the nature of suggestibility 
and also provide information useful for developing measures which assess an individual's suggestibility. Although most studies of this nature have compared child and young adult participants, a few have examined the nature of suggestibility with adolescent samples (Calicchia \& Santostefano, 2004; Muris, Meesters, \& Merckelbach, 2004; Richardson \& Kelly, 1995; Richardson \& Kelly, 2004; Singh \& Gudjonsson, 1992).

With a sample of delinquent adolescents ranging in age from 10 to $16(M$ age $=15.5)$ Richardson and Kelly (1995) found intelligence, as measured by the Wechsler Intelligence Scale for Children - Revised, to be negatively correlated with suggestibility as measured by the GSS. More specifically, the delinquent adolescents with below average intelligence displayed significantly higher levels of suggestibility as evidenced by higher numbers of Yields and Shifts. Also, those participants with poorer memory recall were more suggestible as evidenced by Yield scores but not Shift scores. These researchers also found recall memory as measured by the free recall portion of the GSS to be negatively correlated with suggestibility. Paralleling these findings with an adult sample, Gudjonsson (1983) found higher levels of suggestibility to be significantly related to less accurate memory recall and lower levels of intelligence as measured by the Wechsler Adult Intelligence Scale. Gudjonsson also administered the Eysenck Personality Questionnaire and significant relationships were found between suggestibility and the personality characteristics of neuroticism and social desirability, with higher levels of these two traits being associated with higher levels of suggestibility.

Richardson and Kelly (2004) also investigated the relationship between suggestibility and the personality factors of compliance and social desirability. This sample consisted of institutionalized adolescent males ranging in age from 10-16 ( $M$ age $=15$ years $)$. In this study suggestibility was assessed with the GSS, compliance was assessed with the Gudjonsson 
Compliance Scale, and social desirability was assessed with the Lie Scale portion of the Eysenck Personality Questionnaire. The results indicated that high levels of compliance are related to high levels of Yielding; however no relationship was found between compliance and Shifting. Higher levels of social desirability were also found to be associated with higher levels of suggestibility as evidenced by Yielding but not Shifting. Polczyk (2005) assessed interrogative suggestibility and social desirability with young adults ( $M$ age 22$)$ and found higher levels of social desirability to be related to higher levels of Shifting.

Muris et al. (2004) also assessed individual difference factors related to suggestibility with a delinquent adolescent sample. This study entailed administering the GSS, as well as measures of memory, intelligence, social inadequacy, social desirability, and fantasy proneness to the delinquent adolescents who ranged in age from 14 to $19(M$ age $=16)$. The results indicated that only poorer memory and lower levels of intelligence were associated with suggestibility as evidenced by the overall measure of suggestibility (Yield and Shift scores combined) as well as Yield and Shift scores separately.

Calicchia and Santostefano (2004) conducted a study with participants ranging in age from 10 to 12 and examined the relationship between interrogative suggestibility and gender, visual memory, and attention. These researchers found suggestibility to be related to visual memory such that those with poorer visual memory displayed higher levels of Yield and Shift. These researchers also found that the females in their study were more likely to Yield to suggestive questions. No relationship was found between suggestibility and attention. Singh and Gudjonsson (1992) investigated hostility, attitudes toward authority, intelligence, memory capacity, and field dependence with a sample of adolescent males ranging in age from 11 to 16 years. Higher levels of intelligence and memory capacity were found to be associated with lower 
levels of suggestibility. Lower levels of field dependence (one's tendency to focus on central versus peripheral aspects) were also associated with lower levels of suggestibility. Hostility and attitudes toward authority were not found to be related to suggestibility.

Memory and social desirability are two examples of individual difference factors which have been linked to suggestibility in adults (Gudjonsson, 2003). Although Muris et al. (2004) found social desirability to not be associated with suggestibility in a delinquent adolescent sample, most other researchers have found a relationship between social desirability and suggestibility (Gudjonsson, 1983; Richardson \& Kelly, 2004; Polczyk, 2005). Social desirability broadly refers to a person's desire to be seen in a socially favorable light (Gudjonsson, 2003). Research is lacking which compares the potentially differential influence this factor may have upon adolescents versus young adults. One might predict that social desirability would be a more salient influence on adolescents compared to young adults due to adolescents being more egocentric (Elkind, 1967).

In summary, the literature is lacking in studies which have examined individual difference contributors of suggestibility with nondelinquent adolescents and young adults. The current study further investigates the relationship between suggestibility and previously studied individual difference factors in order to determine if these factors are contributors of suggestibility within an adolescent and young adult sample, as has been found in children and delinquents. Though regressions were used in the current study to determine the unique contribution of these individual difference factors to the components of suggestibility, the factors will not be referred to as predictors, as concurrent data were used, instead they will be referred to as contributors. One such factor which has a strong theoretical link to suggestibility is source monitoring ability. Source monitoring has been linked to suggestibility in studies with children; 
it is an individual difference factor which has not yet been investigated within any adolescent or young adult samples.

\section{Source Monitoring}

Source monitoring refers to "the set of processes involved in making attributions about the origins of memories, knowledge, and beliefs" (Johnson, Hashtroudi, \& Lindsay, 1993, p. 4). The presentation of misinformation after an event during the course of an interview has the potential to cause memory impairment and thus may cause future reports of the event to be inaccurate (Loftus, 1979). This incorporation of misinformation across interviews is referred to as the misinformation effect and is not typically assessed by individual difference measures of interrogative suggestibility. However, the study of interrogative suggestibility does entail the presentation of misinformation in the form of suggestive questions which contain inaccurate information pertaining to the event in question that could presumably lead to later source confusions. Source-monitoring theory attributes inaccurate reports to the individual confusing the source of the information he or she recollected. Based on this assumption, Johnson, Hashtoudi, and Lindsay (1993) claimed fewer false recollections will be reported if individuals make source-monitoring judgments that require them to evaluate the characteristics of their memories.

Source monitoring ability increases with age. In some cases young children (6-year-olds and 8-year-olds) display similar levels of source monitoring skill when compared to adults; however, age differences vary depending upon the type of source monitoring task individuals are presented with. Specifically, young children are less able to accurately monitor the source of their memories when distinguishing between similar experiences and when distinguishing between imagined versus experienced events. Source monitoring ability appears to have an 
inverted U shaped trajectory as it increases from childhood and subsequently decreases in old age. Johnson, Hashtroudi, and Lindsay (1993) found age differences within certain source monitoring tasks when comparing the source monitoring ability of older adults $(M$ age $=70)$ and younger adults $(M$ age $=35)$, with the younger adults displaying more accurate recollections of the source of their memories.

Studies examining the misinformation effect and studies of interrogative suggestibility both entail requiring interviewees to distinguish between the sources of their memories. Those who conduct interviews in forensic settings (police officers, clinicians, social workers, lawyers, etc.) can, intentionally or not, present information within their questions. Those interviewed will then need to distinguish between their memory for the target event and the information presented within interviews. These inaccurate leading or suggestive questions have the potential to impair memory and may lead to confusion as to the source of one's memories (Johnson, Hashtroudi, \& Lindsay, 1993). The ability to accurately identify the source of one's memories is therefore an important skill to explore within forensic interview research.

Witnesses are often interviewed multiple times and with suggestive interview techniques, both of which have the potential to cause source misattributions. As the event in question is discussed more and more, the interviewee's knowledge pertaining to the event may come to include information that is presented within multiple questions and sometimes across multiple interviews. It is understandable then, that individuals with better source monitoring skill might also display lower levels of suggestibility. It may seem as though this issue could be resolved by requiring interviewers in forensic settings to use only nonsuggestive interview techniques; however, due to the need for additional information from witnesses and lack of standardized training these techniques will continue to be used. 
Cavedon, Mega, and Mocellin (2004) compared source monitoring ability and levels of suggestibility in 3-, 4-, and 5-year-olds. These researchers found that regardless of age, those with higher source monitoring ability displayed lower levels of suggestibility. Source monitoring ability was assessed by testing the children's memory of where stimuli were presented and whether they had either seen the stimuli at that location or if they had only heard that the stimuli had been at that location. Suggestibility was assessed with the Italian version of the Video Suggestibility Scales for Children and only the Yield 1 score was used to test for the relationship between source monitoring ability and suggestibility.

Source monitoring ability has not yet been assessed as an individual difference factor in studies of interrogative suggestibility with adolescents and young adults. There is also a need for source monitoring studies which assess age differences between adolescents and young adults. Due to the findings that source monitoring ability increases with age from middle to late childhood (Parker, 1995; Foley, Johnson, \& Raye, 1983), the current study examined whether there were lower levels of source monitoring ability in adolescents compared to young adults.

Source monitoring ability has been assessed in adults with various methods. Some researchers have simply staged experiences and subsequently asked participants to distinguish between them. Often such experiences differ in their modality, such as audio versus visual or imagined actions versus real actions. Source monitoring questions corresponding to this method typically ask the participants if they remember seeing, hearing, experiencing, or imagining what they have recalled (Johnson, Hashtroudi, \& Lindsay, 1993).

The current measure of source monitoring ability has been used by Lindsay and Johnson (1989) and Multhaup, De Leonardis, and Johnson (1999). With this measure, these researchers found that attending to the source of one's memories is related to lower levels of suggestibility, 
as evidenced by lower levels of acquiescing to inaccurate leading questions, within both an undergraduate and older adult sample. This measure requires participants to distinguish between a visual presentation and a narrative which they read silently to themselves. The inclusion of a measure of source monitoring ability in the current study provided for an investigation of a new individual difference factor related to suggestibility as well as allowing for the exploration of potential age differences in source monitoring ability, which has not been previously investigated between adolescents and young adults.

\section{Study Rationale}

In light of the lack of studies which explore the nature of suggestibility and source monitoring ability during adolescence, this study compared this age group to young adults on these dimensions. Age differences in source monitoring ability were assessed and source monitoring ability was also used as an individual difference factor to investigate its relation to suggestibility. Although the previously-cited research has shown an association between memory ability and suggestibility, to date source monitoring ability has not been used as an individual difference factor related to suggestibility in adolescents and young adults. The literature is also lacking in research which includes nondelinquent/noninstitutionalized adolescents. The current study will contribute to the literature by providing findings from a nondelinquent sample of adolescents.

As noted by Calicchia and Santosefano (2004), the development of new measures of suggestibility is important for furthering our knowledge of the nature and contributors of this construct. The new measure of suggestibility used in the current study allowed for a more detailed exploration of the nature of suggestibility as it better creates some of the conditions of interrogative suggestibility as proposed by Gudjonsson and Clark (1986). Specifically, these 
conditions, which must be met for suggestive responses to occur, include uncertainty and interpersonal trust.

The VSSA could be considered to better create uncertainty in that the target event entails the presentation of both visual and auditory information (seeing and hearing dialogue while viewing the video), not just auditory information as with the GSS, which entails reading a narrative. Also, as previously mentioned, the VSSA contains a greater number of questions which are more equally divided into suggestive and nonsuggestive questions, and this might result in a greater perception of interpersonal trust by masking the intent to mislead the participants with suggestive questioning (Gudjonsson \& Clark, 1986).

In addition, this study examined personality traits as individual difference factors which may be contributors of suggestibility, utilizing the Multidimensional Personality Questionnaire Brief Form (MPQ-BF) (Patrick, Curtin, \& Tellegen, 2002; Tellegen, 1982) which contains items that assess the broad dimensions of Constraint, Positive Emotionality, and Negative Emotionality, as well as 11 narrower traits. Previous research with an adolescent sample has revealed that high levels of Negative Emotionality were related to higher levels of delinquent behavior and high levels of Constraint were correlated with lower levels of delinquent behavior (Patrick, Curtin, \& Tellegen, 2002). Researchers have also found delinquents to be more suggestible than nondelinquents as evidenced by higher numbers of Shifts and higher levels of increase in Yield scores from Yield 1 to Yield 2 (Richardson, Gudjonsson, \& Kelly, 1995).

In the MPQ-BF the construct of Constraint pertains to the characteristics of impulsivity and behavioral regulation. The construct of Positive Emotionality includes well being, social potency, achievement, and social closeness. Well-being pertains to characteristics such as optimism. Social potency refers to characteristics such as persuasiveness and leadership 
qualities. Achievement covers characteristics such as being a hard worker and being ambitious. Social closeness refers to being sociable and affectionate. The construct of Negative Emotionality includes stress reaction, alienation, and aggression. Stress reaction refers to qualities such as irritability and being worry-prone. Alienation pertains to persistent feelings such as perceived mistreatment and suspicion of deception. Aggression covers characteristics such as enjoying the distress of others and being vengeful. The Constraint traits include control, harm avoidance, and traditionalism. Control refers to characteristics such as being rationale, organized, and cautious. Harm avoidance pertains to qualities such as disliking danger and disliking risky situations. Traditionalism covers feelings towards moral standards and values. Absorption is a final personality factor which is distinct from the three dimensions Absorption pertains to characteristics such as imagination and thinking in images. As a validity check this measure includes the Unlikely Virtues scale, which is also considered to be a measure of social desirability. In the current study the Unlikely Virtues scale will be used as a measure of social desirability and not as a validity check. Other validity scales included in this measure are the Variable Response Inconsistency scale and the True Response Inconsistency Scale, which identify the presence or absence of inconsistency in responding and yea-saying/nay-saying respectively.

Although the current study investigated of the relationship between suggestibility and the three higher-order personality factors assessed by this measure, two specific traits were predicted to be especially relevant to suggestibility; namely, stress reaction and alienation. These two traits might be relevant to suggestibility due to the interrogative pressure that is present during interviews which use the suggestive technique of providing negative feedback followed by asking a series of questions again. Stress reactivity refers to the characteristics of irritability and 
being worry-prone and was expected to be relevant because interrogative pressure, in the form of negative feedback, has the potential to cause a person to experience interpersonal uncertainty and anxiety (Gudjonsson, 2003), thus, with this added strain, an individual with high stress reactivity might be expected to be more likely to display Shifts.

Different levels of Alienation were also expected to influence an individual's likelihood of assenting to misleading questions. Alienation is characterized by feelings of betrayal and sensitivity to deception. If a person is more likely to experience these feelings then it was posited that they would be more likely to realize that some of the questions being posed to them are misleading, thus dissolving the person's interpersonal trust and making it less likely for them to Yield to suggestive questions (Gudjonsson \& Clark, 1986). Stress reaction and alienation, in addition to the other dimensions of personality assessed by the MPQ-BF, are defined in more detail in a later section along with the description of this measure.

The current study not only adds to the understanding of the nature of suggestibility and its components, it also provides information about other characteristics that were either found to be associated with suggestibility or not, and that where found to either contribute to suggestibility or not be adequate contributors of suggestibility.

\section{Research Questions and Hypotheses}

\section{Research Question 1}

Will age differences be found in Yield, Shift, Total Suggestibility, source monitoring ability, and memory ability between the adolescent and young adult samples?

Hypothesis 1. Based on Richardson et al. (1995), adolescents and young adults are not expected to significantly differ in the number of Yields. 
Hypothesis 2. Based on Richardson et al. (1995), adolescents are expected to display significantly more Shifts compared to young adults.

Hypothesis 3. Adolescents will display higher levels of Total Suggestibility compared to young adults. As Total Suggestibility is the sum of Yields and Shifts, the expected age differences in Shift were expected to contribute to this difference.

Hypothesis 4. Based on Parente's (2001) work with adolescents and young adults and on Adams's (1991) comparison of older and younger adolescents it is expected that the adolescents will display lower levels of memory ability compared to the young adults as evidenced by fewer items recalled during the free recall portion of the VSSA.

Hypothesis 5. Based on Parker (1995) and Foley et al.'s (1983) work with children it is expected that the adolescents will display lower levels of source monitoring ability compared to the young adults, as evidenced by fewer correct responses on the source monitoring test.

\section{Research question 2}

Which individual difference factors will be significant contributors of suggestibility?

Hypothesis 6. Of the individual difference factors, memory skill is expected to have more of an influence on suggestibility (Calicchia \& Santostefano, 2004; Gudjonsson, 1983; Gudjonsson, 2003; Muris et al., 2004; Richardson \& Kelly, 1995).

Hypothesis 7. Of the individual difference factors, social desirability is expected to have more of an influence on suggestibility compared to the other personality factors (Gudjonsson, 1983; Polczyk, 2005; Richardson \& Kelly, 2004).

\section{Research Question 3}

Is source monitoring ability more strongly associated with Yields or Shifts? 
Hypothesis 8 . Source monitoring ability will be more strongly associated with Yields as opposed to Shifts across both age groups (Cavedon, Mega, \& Mocellin, 2004).

\section{Research Question 4}

Will stress reaction and alienation be related to suggestibility?

Hypothesis 9. Higher levels of stress reaction will be associated with higher levels of Shifting, as this was expected to result in a higher level of arousal after negative feedback.

Hypothesis 10. Higher levels of alienation will be associated with lower levels of Yielding, as this was expected to result in awareness of the misleading nature of the questions.

\section{Method}

\section{Participants}

Participants included both an adolescent and a young adult sample. The current study refers to 13- to 17-year-olds as adolescents and 19- to 23-year-olds as young adults. Though many would recognize these two age groups as perhaps being in a similar developmental stage termed emerging adulthood (Arnett \& Taber, 1994), for the aforementioned reasons, discussed in terms of general memory research, there are theoretical justifications for comparisons between these two similar age groups.

A total of 103 adolescents were recruited from area high schools and clubs. The majority of the adolescents $(63 \%)$ were from a rural county southern West Virginia. The remaining adolescents were from a more urban county in northern West Virginia. Upon approval of their instructors, the adolescents recruited from high schools received extra credit for participating. The adolescents ranged in age from 13 to 17 , and their mean age was $15.44(S D=1.04)$. There were 68 females and 35 males, and they were predominantly Caucasian. A total of 97 young adults were recruited from undergraduate psychology classes at a state-sponsored major 
university located in a large town in northern West Virginia. Undergraduate participants received extra credit in one of their psychology courses for their participation. The young adults ranged in age from 19 to 23 , and their mean age was $20.56(S D=.790)$. There were 65 females and 32 males, and they were predominantly Caucasian. In total, the sample included 200 participants, with a mean age of $17.92(S D=2.73), 133$ females and 67 males.

Although college students are a more select group than adolescents attending public high schools, the institution from which the young adults were recruited is believed to have allowed for a wide range of participants to be included in the sample. However the ability to compare these two samples is compromised by the fact that they draw from slightly different populations, as the young adults being college undergraduates distinguishes them from adolescents who may or may not be able to attend college. Thus interpretations of comparisons should take this sampling bias into account.

\section{Materials}

Both the adolescent and the young adult participants completed all of the measures in the same order. All of the participants completed the Multidimensional Personality Questionnaire Brief Form (MPQ-BF), a demographics questionnaire, the Video Suggestibility Scale for Adults (VSSA), and an assessment of source monitoring ability. Constructs and measures are displayed in Table 1.

Personality measure. The MPQ-BF (see Appendix A) contains items which assess the broad dimensions of Constraint, Positive Emotionality, and Negative Emotionality. Constraint pertains to the characteristics of impulsivity and behavioral regulation. The highest possible score one could attain on this variable is 37 . Positive and Negative Emotionality are linked with mood and involve tendencies towards positive and negative emotions. Specifically, the Positive 
Emotionality personality traits include well being, social potency, achievement, and social closeness. The highest possible score one could attain on this variable is 52. The Negative Emotionality traits include stress reaction (14 items), alienation (13 items), and aggression. The highest possible score one could attain on this variable is 39 .

The original MPQ (300 items), developed by Tellegen, was the result of a decade of research pertaining to key dimensions within the personality literature and has been extensively utilized and found to correspond with overt behaviors as evidenced by self-report and observer ratings. The three broad dimensions of personality assessed by the MPQ (Constraint, Positive Emotionality, and Negative Emotionality) have been found to relate to the dimensions of personality assessed by the NEO Personality Inventory. Specifically, the big 5 factors of the NEO-PI are Openness, Conscientiousness, Extraversion, Agreeableness, and Neuroticism and these have been found to significantly correlate with the 3 dimensions of the MPQ. Constraint was found to significantly correlate with Conscientiousness $(r=.46)$ and Openness to experience $(r=-.35)$. Positive Emotionality was found to significantly correlate with Extraversion $(r=-.60)$. Negative Emotionality was found to significantly correlate with Neuroticism $(r=.70)$ and Agreeableness $(r=-.40)$. The brief version of this measure (155 items), developed by Patrick, Curtin, and Tellegen (2002), was used for the current study. The MPQ-BF has been found to correlate highly with the original version as well as have good internal consistency. Pearson correlations between the MPQ and MPQ-BF on the dimensions of Constraint, Positive Emotionality, and Negative Emotionality are .94, .97, and .98 respectively (Patrick et al., 2002).

Demographics measure. The demographics questionnaire included questions of gender, age, class rank, GPA, memory ability, and visual acuity (see Appendix B). 
Suggestibility measure. The VSSA (see Appendix C) entailed showing a video of perpetrators committing two crimes. These crimes are a house burglary and a carjacking, which last five and two minutes respectively. The order of the presentation of the crimes was the same for each participant as it has previously been found that counterbalancing the order did not result in any significant differences. After a delay (the time required to complete the demographics questionnaire and filler tasks) the participants were interviewed with both accurate suggestive and inaccurate suggestive questions. The interview begins with a free recall portion during which the interviewer asks open-ended questions and allows the interviewee to recall all that she or he is able to about the crimes. This is followed by asking a series of yes/no questions, some of which are accurate suggestive and others are inaccurate suggestive. After being asked the series of questions, the participant is given negative feedback and the same series of questions is asked again.

There are a total of 111 questions in this interview, 50 of which are inaccurate leading and 61 of which are accurate leading. Inaccurate leading questions contain misinformation pertaining to the target event and would be considered suggestive whereas accurate leading questions contain factual information pertaining to the event. During the first series of questioning affirmative responses to any of the 50 inaccurate leading questions is defined as a Yield, and so the highest possible score one could attain on Yield is 50. A Shift is defined as a change in an interviewee's answer to any of the 111 questions from the first series of questioning to the second series of questioning, and so the highest possible score one could attain on Shift is 111. The addition of Yield and Shift scores results in the value for Total Suggestibility, and so the highest possible score one could attain on Total Suggestibility is 161. The VSSA differs from the GSS because it presents a visual and auditory target event (video) as opposed to an 
auditory event (narrative), thus making it an assessment that more closely resembles an eyewitness situation. Presenting the target event in video format also allows for visual memory to be assessed. Also, these questions are more equally divided into accurate leading and inaccurate leading, which makes it less likely that those being assessed will realize the intention of the suggestive questions.

Memory measure. The free recall portion of the VSSA was used to assess memory ability. Free recall of the VSSA video entailed asking the participant to tell everything they could remember about the burglary and the carjacking. The principal researcher developed a coding scheme by transcribing and coding the video according to a procedure previously developed by Memon and colleagues which assigns one point for accurate persons, actions, objects, and surroundings (Memon, Wark, Bull, \& Koehnken, 1997). Mentioning a description of any of these 4 items was also counted as one point. For example, mentioning a girl was coded as one point for the person item, also mentioning that the girl had brown hair was coded as another point for the person item. There were 588 total possible items that could theoretically be recalled after seeing the video. This total includes all possible person, action, object, and surrounding characteristics seen during the video. The process of coding the transcription of the video entailed assigning one point for every action and description of an action, person and description of a person, object and description of an object, and surroundings and descriptions of a characteristic of the surroundings. The transcription of the event resulted in a detailed description of all information presented during the video, including everything that was seen and heard.

Gudjonsson (1987) responded to criticisms that this method of assessing memory and its relation to suggestibility was confounded by the fact that memory recall pertains to the same 
topic as the suggestive questions that are later asked. To address this potential problem, Gudjonsson compared the correlations between suggestibility and memory using the previously described method with correlations between these two variables obtained from independent measures of memory and suggestibility. The findings were the same when he compared both of these methods, thus he concluded it is acceptable to assess memory ability (in order to correlate it with suggestibility) with the free recall portion of a measure which also later assesses suggestibility with questions pertaining to the same event.

Source monitoring measure. A measure of source monitoring ability was obtained from Kristi Multhaup, Ph.D. for the purposes of the current study. This measure, which has been used by Lindsay and Johnson (1989) and Multhaup et al. (1999), includes the use of a color slide, two lists of objects, two texts, and a series of questions (see Appendix D). Administering this measure entails presenting a color slide for 20 seconds. This slide is a photograph of an office space with four people and numerous objects. All of the copies of the slide used during data collection were printed out at the same time, with the same printer, in order to ensure that identical photographs were shown to each of the participants. After viewing the slide, participants were asked to read a 400-word text which mentioned some items in the picture and some items that were not in the picture. The participants were required to read this text aloud to the researcher in order to ensure that they had read the text.

After reading the narrative, participants were given instructions for taking the source monitoring test. The 32-item test included eight picture-only items, eight misleading-text only items, eight picture-and-text items, and eight novel items. The order of the questions was randomized with no more than two items from the same category in a row. The objects included in the picture-only and picture-and-text categories are items present in the picture and include 
objects such as a pencil holder, coffee cup, and pinstripe suit. Items in the misleading-text-only and new categories included objects that are conceptually similar to those present in the slide, such as a typewriter, coffeemaker, and coat-rack. The misleading items are mentioned in the text and the novel items were not presented to the participants and are considered to be distracter items.

Social desirability measure. The Unlikely Virtues Scale of the MPQ-BF (see Appendix E) assessed social desirability (Tellegen, 1982). The scale has been used previously as an index of social desirability (Schultheiss, Dargel, \& Rohde, 2003). Previous studies have used validity scales to assess the relationship between suggestibility and social desirability. These scales essentially assess the desire to present yourself in a socially-favorable way. Richardson and Kelly (2004) used a validity scale (the Lie Scale) of the Eysenck Personality Questionnaire to assess social desirability. Polczyk (2005) used the Marlow-Crowne Social Desirability Scale, which is often used to assess response bias on self-report measures, solely as a measure of social desirability. This 14-item scale has a true/false question format and satisfactory reliability (testretest $r=.73)$.

\section{Procedure}

All participants underwent the same procedure. Data collection took place during a single session and all sessions were one-on-one, with an interviewer and a participant being the only individuals present throughout the procedure. There were a total of eleven interviewers involved in data collection, five of which collected data from the young adults and six of which collected data from the adolescents. All were trained undergraduate research assistants or graduate students. Before administering these measures, all of the interviewers received training in order to ensure that each instance of data collection was as uniform as possible. This training included 
instructions on and practice with administering the measures. The interviewers looked over all written self-reports after the participants turned them in to ensure that no responses had been left blank. Any differences seen in the interviewers' rate of speech, inflection of voice, reactions to responses, demeanor, rapport, or responses to interviewee questions were addressed so that such issues could be alleviated and the presentation of the interview might be uniform.

The participants completed the MPQ-BF, watched the videotaped VSSA event, completed the demographics questionnaire, completed word puzzles (as filler tasks), received the VSSA interview, and finally received the source monitoring measure. This order alleviated the issue of bias that could have potentially resulted from presenting the video before administering the MPQ-BF. This order also alleviated the issue of bias in memory recall that could potentially result from administering the source monitoring measure before the VSSA interview. Sessions lasted from an hour and a half to two hours.

\section{Results}

\section{Descriptive Results}

Descriptive statistics for age, Yield, Shift, Total Suggestibility, memory, source monitoring, social desirability, positive emotionality, negative emotionality, constraint, stress reaction, and alienation are displayed in Table 2 for the entire sample. Table 3 displays the same information according to age; this table also indicates which variables were significantly different between the two age groups.

\section{Preliminary Analyses}

In order to rule out the influence of the gender of the interviewer on the measures of suggestibility, a MANOVA was conducted with Yield, Shift, and Total Suggestibility as the dependent variables and gender of the interviewer as the independent variable. No significant 
effects of interviewer gender were seen on Yield, $F(1,199)=2.57, n s$, Shift, $F(1,199)=1.20$, $n s$, or Total Suggestibility, $F(1,199)=2.85, n s$. A MANOVA was also conducted with Yield, Shift, and Total Suggestibility as the dependent variables and gender combinations as the independent variable. The gender combination variable was created by distinguishing between conditions where the interviewee was female and the interviewer was female, the interviewee was male and the interviewer was male, the interviewee was female and the interviewer was male, and the interviewee was male and the interviewer was female. No significant effects of interviewee/interviewer gender were seen on Yield, $F(3,199)=2.56, n s$, Shift, $F(3,199)=$ $2.65, n s$, or Total Suggestibility $F(3,199)=1.29, n s$.

In order to rule out the influence of visual acuity on the measures of suggestibility, two MANOVAs were conducted with Yield, Shift, and Total Suggestibility as the dependent variables and measures of visual acuity as the independent variables. The two measures of visual acuity were assessed by asking the participants if they were wearing their corrective eyewear if they required it and how they would rate the quality of their eyesight. No significant effects of wearing corrective eyewear were seen on Yield, $F(1,143)=1.79$, $n s$, Shift, $F(1,143)=12.56$, $n s$, or Total Suggestibility, $F(1,143)=4.87, n s$, and no significant effects of quality of eyesight were seen on Yield, $F(4,199)=5.58$, $n s$ Shift, $F(4,199)=12.48, n s$, or Total Suggestibility, $F$ $(4,199)=27.07, n s$.

In order to rule out the influence of visual acuity on the performance of the participants on the source monitoring task two one-way ANOVAs were conducted with both measures of visual acuity. No significant effects of wearing corrective eyewear were seen on source monitoring ability, $F(1,143)=.38, n s$, and no significant effect of quality of eyesight were seen on source monitoring ability $F(4,199)=1.80, n s$. 


\section{Age Differences}

Statistics, including the means for each age group on the following measures, are displayed in Table 3.

Suggestibility. Analyses were conducted to determine if there were differences in Yield, Shift, and Total Suggestibility between the adolescent and young adult samples. The total number of affirmative responses to inaccurate questions was summed and this value was the participants' data for Yield. To address hypothesis 1, that the adolescents and young adults would not differ in the number of Yields, a one-way ANOVA was conducted to assess age differences in Yield, a significant difference emerged with adolescents $(M=22.73)$ being more likely to Yield compared to young adults $(M=19.89), F(1,199)=44.56, p=.001, d=.95$.

The total number of changes in responses from the first round of questioning to the second round of questioning were summed and this value served as the participants' data for Shift. To address hypothesis 2 , that adolescents would display significantly more Shifts compared to young adults, a one-way ANOVA was conducted to assess age differences in Shift, and no significant difference was seen between the adolescents $(M=11.03)$ and the young adults $(M=9.84)$ on this measure, $F(1,199)=2.98, n s$.

The total number of Yields and Shifts were summed and this value served as the participants' data for Total Suggestibility. To address hypothesis 3, that the adolescents would display higher levels of suggestibility compared to the young adults, a one-way ANOVA was conducted to assess age differences in Total Suggestibility, a significant difference emerged with adolescents $(M=34.03)$ displaying higher levels of suggestibility compared to young adults ( $M$ $=29.72), F(1,199)=20.22, p=.001, d=.64$. 
Memory. Analyses were conducted to determine if there were differences in memory ability between the adolescent and young adult samples. Memory ability was assessed with the free recall portion of the VSSA, the beginning of the interview where the participant is asked to recall everything that they can about the events. Coding of the free recall portion of the VSSA was completed by two independent coders who were trained to follow a coded transcription of the VSSA video and assign one point for every accurate person, action, object, and surrounding mentioned by the participants. Accuracy of their coding was checked periodically throughout the time they required to complete the coding for all of the participants. Inter-coder agreement for the total number of accurate items recalled during free recall was $97 \%$, this included items for both the robbery and carjacking. This inter-coder agreement was assessed with a reliability analysis yielding an alpha $(r=.97)$. The total number of items recalled by the participants was summed and this served as their data on this measure.

To address hypothesis 4, that the adolescents will display lower levels of memory ability compared to the young adults, a one-way ANOVA was conducted to assess age differences in memory recall, a significant difference was revealed, with adolescents $(M=54.67)$ recalling significantly fewer details compared to young adults, $(M=70.13), F(1,199)=20.96, p=.001, d$ $=.65$. Although these values may seem indicative of low overall memory recall as the total number of possible items that could be recalled was 588 , it should be noted that this total takes into account every single possible detail that could theoretically be recalled and this total was come to by extensive and repetitive reviews of the video.

Source Monitoring. Analyses were conducted to assess age differences in source monitoring ability. This memory skill was assessed with a source monitoring test which required the participants to identify whether they remembered an item as being presented in a picture, 
being read in a narrative, being in both, or being in neither. The total number of accurate responses was used as the participants' data on this measure. To address hypothesis 5 , that the adolescents would display lower levels of source monitoring ability compared to the young adults, a one-way ANOVA was conducted to assess age differences in source monitoring ability, a significant difference was revealed, with adolescents $(M=16.24)$ displaying lower levels of source monitoring ability compared to the young adults, $(M=17.32), F(1,199)=4.86, p=.029$, $d=.31$.

\section{Contributors of Suggestibility}

Pearson correlations were used to examine the relation among the variables. Correlations were conducted with Yield, Shift, Total Suggestibility and memory, source monitoring, social desirability, positive emotionality, negative emotionality, constraint, stress reaction, and alienation. Table 4 displays these correlations for the entire sample. Table 5 displays the same information according to age. For the entire sample significant correlations were seen between memory and the three measures of suggestibility. For Yield, Shift, and Total Suggestibility, higher levels of memory ability were associated with lower levels of suggestibility. Source monitoring correlated significantly with Shift and Total Suggestibility with higher levels of source monitoring ability being associated with lower levels of suggestibility. Social desirability also correlated positively with the three components of suggestibility. Higher levels of positive emotionality were associated with lower levels of Total Suggestibility. Higher levels of negative emotionality were associated with higher levels of Yield and Total Suggestibility. Higher levels of alienation were associated with higher levels of Yield, Shift, and Total Suggestibility.

Correlations were also conducted with the age groups separated. The young adults' higher levels of memory ability were associated with lower levels of Yield. With the adolescents 
higher levels of memory ability were associated with lower levels of Shift, and Total Suggestibility. Higher levels of source monitoring ability were associated with lower levels of Shift and Total Suggestibility for both the adolescent and young adult samples. Higher levels of social desirability were associated with higher levels of Shift and Total Suggestibility for both the adolescent and young adult samples.

To address Research question 2, asking which individual difference factors would be significant contributors of suggestibility, a series of regressions were conducted with Yield, Shift, and Total Suggestibility.

In the regressions used to assess contributors of Yield, Shift, and Total Suggestibility, the order of the steps for entering the independent variables were determined based upon previous literature that has linked suggestibility to these factors and results of correlational analyses conducted with the measures of suggestibility and these factors. Specifically, memory ability has often been linked to measures of suggestibility (Gudjonsson, 1983; Muris et al., 2004) and in the current study was found to significantly correlate with suggestibility, thus memory ability was entered into the second step of these regressions. Source monitoring is considered to be a specific type of memory ability. This skill has been found to relate to suggestibility in children, with those who display higher source monitoring ability displaying lower levels of suggestibility (Cavedon et al., 2004). Source monitoring was also found to correlate significantly with suggestibility, thus this factor was entered into the third step of these regressions. Higher levels of social desirability has been found to be associated with higher levels of suggestibility in some studies (Richardson et al., 2004), but not others (Muris et al., 2004). Due to these conflicting findings and the significant correlations in the current study between social desirability and suggestibility, this factor was entered into the fourth step of the regressions. A goal of the current 
study was to investigate the relationship between other, less studied personality factors. For this reason the three main dimensions of the MPQ were entered into the fifth step of the regressions. As age differences were also a major interest in the current study age interactions were entered as the sixth step in these regressions. The interaction terms were created by first centering and then multiplying the variables.

Yield. In order to test for contributors of Yield a hierarchical regression was conducted with Yield as the dependent variable and memory, source monitoring, social desirability, positive emotionality, negative emotionality, constraint, age by memory, age by source monitoring, and age by social desirability entered as the independent variables. These independent variables were examined for multicollinearity. Both the variance inflation factors (all less than 1.5) and the collinearity tolerances (all greater than .69) indicated that the independent variables were not highly correlated and thus the $\beta$ s were stable.

As displayed in Table 6, Step 1 of the model with age as a contributor was significant, $F$ $(1,198)=44.56, p=.001, R^{2}=.18$. In Step 2 , the addition of memory ability as a contributor resulted in a significant model, $F(2,197)=26.53, p=.001$. This equation accounted for $21.2 \%$ of the variance in Yield. In Step 2 the addition of memory ability with age resulted in a significant increment in $R^{2}, \Delta F(1,197)=7.13, \Delta R^{2}=.03$. The additions of Steps 3 through 6 of the model resulted in significant models, though they did not result in a significant increment in $R^{2}$

Shift. In order to test for contributors of Shift a hierarchical regression was conducted with Shift as the dependent variable and memory, source monitoring, social desirability, positive emotionality, negative emotionality, constraint, age by memory, age by source monitoring, and age by social desirability entered as the independent variables. These independent variables were 
examined for collinearity. Both the variance inflation factors (all less than 1.5) and the collinearity tolerances (all greater than .69) indicated that the independent variables were not highly correlated and thus the $\beta$ s were stable.

As displayed in Table 7, Step 1 of the model with age as a contributor was not significant, $F(1,198)=2.98, n s$. In Step 2 the addition of memory ability as a contributor resulted in a significant model, $F(1,197)=7.81, p=.001$. The addition of memory ability with age resulted in a significant increment in $R^{2}, \Delta F(2,197)=12.46, \Delta R^{2}=.06$. In Step 3 , the addition of source monitoring as a contributor resulted in a significant model, $F(3,196)=8.19$, $p=.001$. The addition of source monitoring to the equation resulted in a significant increment in $R^{2}, \Delta F(1,196)=8.36, \Delta R^{2}=.04$. In Step 4 , the addition of social desirability as a contributor resulted in a significant model, $F(4,195)=9.06, \mathrm{p}=.001$. The addition of social desirability as a contributor resulted in a significant increment in $R^{2}, \Delta F(1,195)=10.51, \Delta R^{2}=.05$. After Step 4 this equation accounted for $15.7 \%$ of the variance in Shift. The additions of Steps 5 and 6 of the model resulted in significant models, though they did not result in a significant increment in $R^{2}$

Total Suggestibility. In order to test for contributors of Total Suggestibility, a hierarchical regression was conducted with Total Suggestibility as the dependent variable and memory, source monitoring, social desirability, positive emotionality, negative emotionality, constraint, age by memory, age by source monitoring, and age by social desirability entered as the independent variables. These independent variables were examined for collinearity. Both the variance inflation factors (all less than 1.5) and the collinearity tolerances (all greater than .69) indicated that the independent variables were not highly correlated and thus the $\beta$ s were stable. 
As displayed in Table 8, Step 1 of the model with age as a contributor resulted in a significant model, $F(1,198)=20.22, p=.001$. In Step 2 the addition of memory ability as a contributor resulted in a significant model, $F(2,197)=20.74, p=.001$. The addition of memory ability with age resulted in a significant increment in $R^{2}, \Delta F(1,197)=19.39, \Delta R^{2}=.08$. In Step 3 , the addition of source monitoring as a contributor resulted in a significant model, $F(3,196)=$ $17.01, p=.001$. The addition of source monitoring to the equation resulted in a significant increment in $R^{2}, \Delta F(1,196)=8.07, \Delta R^{2}=.03$. In Step 4 , the addition of social desirability as a contributor resulted in a significant model, $F(4,195)=16.16, p=.001$. The addition of social desirability as a contributor resulted in a significant increment in $R^{2}, \Delta F(1,195)=11.00, \Delta R^{2}=$ .04. After Step 4 this equation accounted for $24.9 \%$ of the variance in Total Suggestibility. The additions of Step 5 and 6 resulted in significant models, though there was not a significant increment in $R^{2}$.

To address Hypothesis 6, that of the individual difference factors memory ability was expected to have more of an influence on suggestibility, the correlations for memory and Yield, Shift, and Total Suggestibility from the previous regressions were converted to z scores and it was found that across these three measures of suggestibility their relation to memory recall was not significantly different (all less than -1.06). Specifically, between Yield and Shift, $z=-.22$, between Yield and Total Suggestibility, $z=-.84$, and between Shift and Total Suggestibility $z=$ -1.06. This indicates that memory and its relation to these measures is comparable across these regression analyses. Also, the $\beta$ s for Yield $(\beta=-.18)$, Shift, $(\beta=-.21)$, and Total Suggestibility $(\beta$ $=-.26$ ), were similar and these $\beta$ s were the highest of all of the other individual difference factors for Yield, and all except social desirability for Shift and Total Suggestibility. 
To address Hypothesis 7, that of the individual difference factors, social desirability was expected to have more of an influence on suggestibility compared to the other personality factors, it was found in the previous regressions that social desirability was the only unique contributor of suggestibility of all of the personality factors (social desirability, positive emotionality, negative emotionality, and constraint). Specifically, social desirability was significant in contributing to Shift and Total Suggestibility, and the $\beta$ s were also similar for Shift $(\beta=.26)$ and Total Suggestibility $(\beta=.26)$

\section{Additional Individual Differences Analyses}

To address Research question 3, concerning source monitoring and its relation to suggestibility, Pearson correlations were conducted with source monitoring and yield and shift. As stated by Hypothesis 8, source monitoring was expected to be more strongly associated with Yields as opposed to Shifts. A Pearson correlation was conducted with source monitoring and Yield and a significant correlation was not found. The Pearson correlation conducted with source monitoring and Shift was significant, $(r=-.25)$ indicating that higher levels of source monitoring ability were associated with lower levels of Shifts (see Table 4). Analyses were also conducted with the adolescent and young adult samples separately; correlations between source monitoring and Yield were not significant within either age group. Shift was also examined within both age groups and the correlation between source monitoring and Shift was significant in both the adolescent $(r=-.24)$ and young adult $(r=-.23)$ samples (see Table 5).

To address Research question 4, concerning stress reaction and alienation and their relation to suggestibility, Pearson correlations were conducted. As stated by Hypothesis 9, higher levels of stress reaction were expected to be associated with higher levels of Shifting, however these two variables were not found to be significantly correlated in the overall sample or within 
either of the age groups. As stated by Hypothesis 10, higher levels of alienation were expected to be associated with lower levels of Yielding. Alienation was found to correlate significantly with Yield $(r=.24)$ in the overall sample, indicating that higher levels of alienation were actually associated with higher levels of Yielding (see Table 4). No significant correlations were seen within both of the age groups.

\section{Discussion}

The main purpose of the current study was to investigate age differences in suggestibility and the influence of related individual difference factors on suggestiblity. Age differences in assenting to misleading questions pertaining to crimes (Yield) and changes in responses to these questions after exposure to negative feedback from an interviewer (Shift) were assessed, as well as an overall measure of interrogative suggestibility: the sum of Yields and Shifts (Total Suggestibility). This is the first study to compare nondelinquent samples of adolescents and young adults on these constructs. This was accomplished with a measure of suggestibility that utilizes a videotaped target event and contains roughly equal numbers of accurate and inaccurate leading questions. These characteristics of the VSSA are important as they are believed to more closely approximate a real life eyewitness situation.

Another goal of the current study was to investigate the contributing power of individual difference factors associated with suggestibility. Memory, source monitoring, and certain personality factors have been found to relate to measures of suggestibility in previous studies. The current study is the first to investigate their contributive relationship with a more forensically appropriate measure of suggestibility with nondelinquent samples of both adolescents and young adults. The assessment of such factors furthers our understanding of the nature of suggestibility, particularly at these two stages of development. 
Major findings of this study include significant differences in Yield and Total Suggestibility between the adolescent and young adult participants, with adolescents displaying higher levels of suggestibility. Another interesting and important age difference finding was that the adolescent participants displayed lower levels of source monitoring ability compared to the young adults. This is the first study to compare adolescent and young adults on this construct. Another major finding is discovering that certain individual difference factors were significant contributor of suggestibility above and beyond age. For Yield, memory was found to be a consistent contributor and the only significant contributor of this component of suggestibility. For Shift, age was not a significant contributor; instead memory, source monitoring, and social desirability contributed significantly to the variance for this component of suggestibility, with social desirability contributing to Shift above both memory and source monitoring. For Total Suggestibility, age, memory, source monitoring, and social desirability contributed significantly to the variance for this measure and, again with social desirability contributing to Total Suggestibility above both memory and source monitoring.

\section{Age Differences}

Suggestibility. Significant differences were seen between the adolescent and young adult participants on measures of both Yield and Total Suggestibility. Although it was hypothesized that age differences would be seen in Shift, this was not found. Richardson, Gudjonsson, and Kelly (1995) found adolescents to Shift significantly more than adults. Though the adolescents in Richardson et al.'s study were similar in age to the current sample of adolescents, the adults in Richardson et al.'s study were older ( $M$ age 30) than the young adults in the current study ( $M$ age 21). This may account for the lack of the expected significant difference in levels of Shift; perhaps the age difference in the current study was not great enough to result in meaningful 
differences in Shift. Also, both the adolescent and adult samples in their study were offenders. These differences in delinquency and age may account for the conflicting age differences found in the current study.

It is interesting to note that it appears these age groups do not appear to be any more susceptible to social pressure to change their responses to questions of a forensic nature after the presentation of negative feedback (Shift). On the VSSA, this social component of suggestibility is apparently stable from adolescence into early adulthood. However, as significant differences were seen in levels of Yielding between the adolescent and young adult participants in the current study, it appears that this cognitive component of suggestibility does differ between these two age groups. This may be best explained in terms of general cognitive development that occurs from adolescence to young adulthood. Significant differences in memory recall of have been found previously between adolescents and young adults (Parente, 2001). Just as significant differences in various measures of memory are seen between these age groups, differences in this cognitive component of suggestibility were found in the current sample. Though Richardson et al. (1995) found no significant differences in Yield between adolescents and adults, it should be noted again that their sample included only delinquents; of the adults some were institutionalized and of the adolescents all were institutionalized.

It may be that delinquent individuals differ from nondelinquent individuals in both cognitive and social characteristics and this could be a potential explanation for these conflicting findings. Researchers have found a link between lower levels of intelligence and delinquency (Hirschi \& Hindelang, 1977) and poorer perceived social competence and delinquency (Cole, Chan, \& Lytton, 1989). Overall when both juvenile delinquents and adult offenders have been compared to nondelinquent samples they have been found to display lower levels of intelligence 
and specific personality differences, including higher levels of impulsiveness, suspicion, defiance, and social assertion (Wilson \& Herrnstein, 1985). When comparing previous studies with offenders and the current study with nonoffenders, these differences should be taken into account.

Though perhaps driven by the differences in Yield, there was a significant difference in Total Suggestibility between the two age groups. These findings of age difference in suggestibility with two nondelinquent samples contribute to the literature in this area and our understanding of developmental differences in these constructs. It is important to study suggestibility with nondelinquent individuals so that we may understand this construct and apply subsequent findings to the many nondelinquent victims and witnesses who receive forensic interviews.

Memory. Ryan (1990) encouraged other researchers to investigate age difference in memory efficiency across adolescence and into early adulthood, due to previous literature that focuses only on more disparate age groups. Previous studies have found adolescents to display significantly lower levels of memory ability compared to young adults (Adams, 1991; Ryan, 1991; Parente, 2001). The current study provided a comprehensive assessment of explicit memory for two forensically relevant events. Explicit memory refers to conscious recollections of previously presented information that may be assessed with free recall as well as cued recall. The participant's memory for the two crimes (carjacking and burglary) was measured with a coding procedure that allowed for a detailed assessment of memory recall. The assignment of one point for every person, action, object, surrounding, and their characteristics that could possibly be recalled after viewing this target event is considered to be a comprehensive method of assessing memory recall. The young adults displaying higher levels of memory recall for these 
crimes is an important finding for both the cognitive developmental literature and criminal investigations including these age groups.

Source monitoring. Though source monitoring ability has been shown to increase across childhood, it is of interest that this skill is markedly different between these two age groups. Source monitoring ability is believed to be an important skill in the accurate recollection of memories and a variable which influences levels of suggestibility. Due to the finding that adolescents are lacking in this ability the use of source monitoring training may be applicable. Thierry and Spence (2002) found that when young children were trained to attend to the source of their memories they were then able to apply this improved ability in a later recall task, resulting in more accurate recall and less suggestibility. These researchers state that one reason for seeing higher levels of suggestibility in young children is that they are less able to scrutinize the origins of their memories. Perhaps with adolescents as well, source monitoring training might result in more accurate recall and less suggestibility.

In relation to suggestibility, source monitoring may be a source of the difference in suggestibility between these age groups. Yield, again reflects a cognitive component of suggestibility. Perhaps the finding of a difference in source monitoring ability lends evidence to the interpretation that the age differences in Yield were due to a difference in overall cognitive memory-based abilities.

\section{Individual Differences}

Contributor of Yield. Above age, memory recall was found to be the only significant contributor of Yield. As Yield is considered to be the more cognitive memory-based component of interrogative suggestibility, it is not surprising that memory recall accounted for so much of the variance in Yield. It appears that source monitoring is not a skill that is essential when 
determining answers to misleading questions. Perhaps a person's memory must be challenged prior to her or him drawing upon this particular memory skill.

Contributors of Shift. Above age, the additions of memory, source monitoring, and social desirability significantly contributed to Shift. It appears that source monitoring is important when the accuracy of an individual's memory has been challenged, perhaps driving the person to utilize this skill. In regard to social desirability it appears that this more social component of interrogative suggestibility is in fact influenced by an individual's desire to be seen in a favorable light. This individual difference factor is important to consider as it contributed to Shift above age, memory, and source monitoring. One's level of social desirability is considered to be a strong contributor to one's likelihood to change one's responses after the presentation of negative feedback.

Contributors of Total Suggestibility. The findings for Total Suggestibility were very similar to those for Shift. It appears that when determining the contributions to overall interrogative suggestibility it is important to take memory, source monitoring, and social desirability into account. Social desirability again contributed to Total Suggestibility above age, memory, and source monitoring. These findings lend more support to the assertion that the desire to be seen in a favorable light has a strong impact upon an individual's level of suggestibility.

Overall these findings may contribute to the development of forensic screening tools that can be used to assess the suggestibility of an individual more accurately than present measures. Perhaps the addition of measures of these individual difference factors that were found to contribute to suggestibility would result in adequate screening measures that could be scientifically tested and later applied in a legal setting. 


\section{Additional Individual Differences Analyses}

Source monitoring. The expected relationship between source monitoring and Yields was not found. Though Cavedon et al. (2004) found that higher levels of source monitoring ability was associated with lower levels of Yielding, it is important to note that their study was conducted with children. A goal of the current study was to investigate the relationship between suggestibility and source monitoring with adolescents. Due to the lack of a significant relationship between Yield and source monitoring it appears that this specific type of memory ability is not an ability that is vital to initial decisions to assent or not assent to misleading questions.

The finding of a significant relationship between source monitoring and Shift is surprising as source monitoring would be considered to be a more cognitive ability; whereas Shift as a construct is considered to be a social component of suggestibility. The finding that higher levels of source monitoring ability were associated with lower levels of Shifting may imply that when the accuracy of one's responses has been brought into question then a person is likely to draw upon their source monitoring skill in order to determine the correct answer to the questions. Those who are better able to distinguish between information remembered in the actual event and information contained in the question will be less likely to change their responses to questions after negative feedback.

Johnson et al. (1993) describe source monitoring as a conscious process that individuals will utilize when they wish to remember the origins of information. Perhaps an effect of the negative feedback presented to the participants in the current study was that it resulted in them more closely scrutinizing their memories of the event, subsequently drawing on their source 
monitoring skills, and thus being more confident in their original responses and not Shifting their answers if their source monitoring ability was stronger.

Stress reaction. No significant relationships were found between stress reaction and Shift. Stress reaction is described as a measure of irritability and being worry prone. This personality characteristic was expected to be related to Shift due to the use of interrogative pressure used in the current measure of suggestibility and the belief that this will create interpersonal uncertainty and anxiety (Gudjonsson, 2003). Those who are already at a higher state of arousal on such dimensions were expected to be more likely to change their responses after being exposed to interrogative pressure in the form of negative feedback. As no significant findings were seen it appears that this personality characteristic does not relate to changing one's responses after negative feedback. Perhaps the presentation of the negative feedback resulted in a level of interrogative pressure that overrode any preexisting personality differences in the participants, making them equally likely to Shift regardless of this dimension of their personalities.

Alienation. It was expected that higher levels of alienation would be associated with lower levels of Yielding. Alienation is described as being prone to experience feelings of betrayal and sensitivity to deception. It was expected that individuals with such a personality characteristic would be more likely to be suspicious of their interviewer's intentions and suspect that they were purposely being asked misleading questions, thus reducing their trust and making it less likely for them to Yield (Gudjonsson \& Clark, 1986). This was not the case, in fact the opposite relationship was found between alienation and Yielding. It should be noted that this is the first study that has investigated the relationship between alienation and suggestibility. As higher levels of alienation were found to be associated with a higher number of Yields it appears that individuals who are more sensitive to deception are more likely to assent to misleading 
questions. A possible explanation for this finding could be that these individuals are less affected by the realization that they are being asked misleading questions due to their assumption that there is widespread deception in their lives and so they assent to more misleading questions because they are less aroused by the awareness of this deception.

In summary, this study revealed important age differences in measures of interrogative suggestibility, memory, and source monitoring. The current study also contributed to this area of research by investigating which individual difference factors are adequate contributors of measures of interrogative suggestibility and which are not. Significant age differences were found in measures of Yield, Total Suggestibility, memory recall, and source monitoring ability. These differences in interrogative suggestibility are important to consider in a forensic context where an array of ages serve as witnesses. These findings may be applied to the many nondelinquent victims and witnesses who receive forensic interviews.

Age differences in the recollection of crimes are also very applicable to a forensic context. The adolescents in the current study were less able to recall details pertaining to the two crimes they witnessed. Source monitoring also differed between these two age groups, this finding furthers our understanding of the developmental trajectory of this particular cognitive memory-based ability. Also, as source monitoring ability was found to be a significant contributor of Yield and Total Suggestibility, above both age and memory ability, this is considered to be an important individual difference factor that should be taken into account when assessing levels of interrogative suggestibility.

Other individual difference variables that were found to contribute to suggestibility included memory and social desirability. Differences were found in the contribution of these variables depending upon which component of suggestibility was being explored. Specifically, 
with Yield, memory served as a contributor over the influence of age. With Shift memory, source monitoring, and social desirability significantly contributed to the prediction, with social desirability contributing over the influence of both memory and source monitoring. Findings similar to those of Shift were seen with Total Suggestibility. These findings emphasize the importance of social desirability in assessing interrogative suggestibility. This characteristic should also be taken into account when assessing levels of interrogative suggestibility.

\section{Limitations and Future Directions}

Limitations of the current study include the use of a special sample of young adults, specifically only those who attend college. This may have resulted in preexisting differences in the two age groups that were compared, though it should be noted that the university the undergraduates attended is a land-grant institution with a fairly open admissions policy. The participants were also predominantly female. Future studies should include a sample of young adults that is more representative of the population as a whole. Another limitation is the use of a newly developed measure of interrogative suggestibility. Though this measure was believed to be, for the aforementioned reasons, a more accurate assessment of interrogative suggestibility, this issue nonetheless makes it difficult to compare the findings of the current study to previous research in this area. Future studies should also include the VSSA so that the current findings might be comparable and more accurate assessments of interrogative suggestibility might be provided for these ages.

Another limitation that relates to the use of the VSSA is the use of a video as the target event. There may be significant differences seen between recollections of a video and recollections of a live event and how suggestible individuals are likely to be when being 
interviewed about a live event versus a videotaped event. Future studies should use similar methods to compare the use of a videotaped event to the use of a live event.

Though the current study found certain individual difference factors to be adequate or inadequate contributors of suggestibility it is important for future research to replicate these findings. Other individual difference factors should be investigated as well. Perhaps similar findings would be discovered if other individual difference factors that have been found to be associated with suggestibility in children were investigated. As intelligence has consistently been found to be associated with suggestibility (Gudjonsson, 1983) this personal characteristic should be investigated with a design similar to the current study in order to determine its contribution. Also, as social desirability was found to be such an important contributor, other constructs associated with self-presentation might be investigated, in addition to other more general social characteristics, such as social competence and measures of various social skills.

\section{Conclusions and Applications}

This study revealed interesting age differences in suggestibility and major cognitive abilities, as well as findings that specific individual difference factors are unique contributors of interrogative suggestibility and its components. Though it is important to replicate these findings the conclusion based on the results of this study is that adolescents and young adults are sufficiently different on some constructs and these differences should be taken into account in the research and application of knowledge pertaining to this area of study. These findings may be applied within the criminal justice system as witnesses may be of any age and victims and others who receive forensic interviews include those who are not prior or current offenders. Law enforcement personnel should be aware that age and personal characteristics will impact witness accuracy and levels of suggestibility. 


\section{References}

Adams, C. (1991). Qualitative Age Differences in Memory for Text: A Life-Span Developmental Perspective. Psychology and Aging, 6, 323-336.

Arnett, J. J. \& Taber, S. (1994). Adolescence terminable and interminable: When does adolescence end? Journal of Youth and Adolescence, 23, 517-537.

Belli, R. F., Lindsay, D. S., Gales, M. S., \& McCarthy, T. T. (1994). Memory impairment and source misattribution in postevent misinformation experiments with short retention intervals. Memory and Cognition, 22, 40-54.

Bruck, M. \& Ceci, S. J. (1999). The suggestibility of children's memory. Annual Review of Psychology, 50, 419-439.

Bruck, M. \& Melnyk, L. (2004). Individual Differences in Children's Suggestibility: A Review and Synthesis. Applied Cognitive Psychology, 18, 947-996.

Calicchia, J. A. \& Santostefano, S. (2004). The assessment of interrogative suggestibility in adolescents: Modalities, gender, and cognitive control. North American Journal of Psychology, 6, 1-12.

Cassel, W. S. \& Bjorklund, D. F. (1995). Developmental patterns of eyewitness memory and suggestibility: An ecologically based short-term longitudinal study. Law and Human Behavior, 19, 507-532.

Caruso, J. C., Witkiewitz, K., Belcourt-Dittloff, A., \& Gottlieb, J. D. (2001). Reliability of scores from the Eysenck Personality Questionnaire: A reliability generalization study. Educational and Psychological Measurement, 61, 675-689.

Cavedon, A., Mega, C., Mocellin, S. (2004). Video suggestibility scale for children and source monitoring. Unpublished Manuscript, University of Padova, Padova, Italy. 
Ceci, S. J., \& Bruck, M. (1993). Suggestibility of the child witness: A historical review and synthesis. Psychological Bulletin, 113, 403-439.

Cole, P. G., Chan, L K., \& Lytton, L. (1989). Perceived competence of juvenile delinquents and nondelinquents. Journal of Special Education, 23, 294-302.

Eisen, M. L., Winograd, E., \& Quin, J. (2002). Individual differences in adults' suggestibility and memory performance. In M. L. Eisen, J. A. Quas, \& G. S. Goodman (Eds.), Memory and Suggestibility in the Forensic Interview (pp.205-234). Mahwah, NJ: Lawrence Erlbaum Associates.

Elkind, D. (1967). Egocentrism in adolescence. Child Development, 38, 1025-1034.

Endres, J. (1997). The suggestibility of the child witness: The role of individual differences and their assessment. The Journal of Credibility Assessment and Witness Psychology, 1, 4467.

Faris, P. D., Ghali, W. A., Brant. R., Norris, C.M., Galbraith, P.D., and Knudtson, M.L., (2002). Multiple imputation versus data enhancement for dealing with missing data in observational health care outcome analyses. Journal of Clinical Epidemiology, 55, 184191.

Fichman, M. \& Cummings, J. N. (2003). Multiple imputation for missing data: Making the most of what you know. Organizational Research Methods, 6, 282-308.

Foley, M. A., Johnson, M. K., \& Raye, C. L. (1983). Age-related change in confusion between memories for thoughts and memories for speech. Child Development, 54, 51-60.

Gudjonsson, G. H. (1983). Suggestibility, intelligence, memory recall and personality: An experimental study. British Journal of Psychiatry, 142, 35-37. 
Gudjonsson, G. H. (1984). A new scale of interrogative suggestibility. Personality and Individual Differences, 5, 303-314.

Gudjonsson, G. H. (1987). The relationship between memory and suggestibility. Social Behaviour, 2, 29-33.

Gudjonsson, G. H. (2003). The psychology of interrogations and confessions: A handbook. West Sussex, England: Wiley.

Gudjonsson, G. H., \& Clark, N. K. (1986). Suggestibility in police interrogation: A social psychological model. Social Behaviour, 1, 83-104.

Gudjonsson, G. H., \& Sigurdsson, J. F. (1996). The relationship of confabulation to the memory, intelligence, suggestibility, and personality of prison inmates. Applied Cognitive Psychology, 10, 85-92.

Hirschi, T. \& Hindelang, M. J. (1977). Intelligence and delinquency: A revisionist review. American Sociological Review, 42, 571-587.

Johnson, M. K., Hashtroudi, S., Lindsay, D. S. (1993). Source monitoring. Psychological Bulletin, 114, 3-28.

Lindsay, D. S. \& Johnson, M. K. (1989). The eyewitness suggestibility effect and memory for source. Memory and Cognition, 17, 349-358.

Loftus, E. F., Miller, D. G., \& Burns, H. J. (1978). Semantic integration of verbal information into visual memory. Journal of Experimental Psychology: Human Learning and Memory, 4, 19-31.

Loftus, E. F. (1979). Reactions to blatantly contradictory information. Memory and Cognition, 7, $368-374$.

McFarlane, F., Powell, M. B., \& Dudgeon, P. (2002). An examination of the degree to which IQ, 
memory performance, socio-economic status and gender predict young children's suggestibility. Legal and Criminological Psychology, 7, 227-239.

Memon, A., Walk, L., Bull, R., \& Koeknken, G. (1997). Isolating the effects of the cognitive interview techniques. British Journal of Psychology, 88, 179-198.

Multhaup, K. S., De Leonardis, D. M., \& Johnson, M. K. (1999). Source memory and eyewitness suggestibility in older adults. The Journal of General Psychology, 126, 74-84.

Muris, P., Meesters, C., \& Merckelbach, H. (2004). Correlates of the Gudjonsson Suggestibility Scale in delinquent adolescents. Psychological Reports, 94, 264-266.

Parker, J. F. (1995). Age differences in source monitoring of performed and imagined actions on immediate and delayed tests. Journal of Experimental Child Psychology, 60, 84-101.

Parente, D. (2001). Implicit and Explicit Memory in Junior High and College Students. Psychological Reports, 88, 313-315.

Patrick, C. J., Curtin, J. J., \& Tellegen, A. (2002). Development and validation of a brief from of the multidimensional personality questionnaire. Psychological Assessment, 14, 150-163.

Polczyk, R. (2005). Interrogative suggestibility: Cross-cultural stability of psychometric and correlational properties of the Gudjonsson Suggestibility Scales. Personality and Individual Differences, 38, 177-186.

Richardson, G., Gudjonsson, G. H., \& Kelly, T. P. (1995). Interrogative suggestibility in an adolescent forensic population. Journal of Adolescence, 18, 211-216.

Richardson, G. \& Kelly, T. P. (1995). The relationship between intelligence, memory, and interrogative suggestibility in young offenders. Psychology, Crime, and Law, 1, 283-290.

Richardson, G. \& Kelly, T. P. (2004). A study in the relationship between interrogative suggestibility, compliance and social desirability in institutionalized adolescents. 
Personality and Individual Differences, 36, 485-494.

Ryan, C. M. (1990). Age-related improvement in short-term memory efficiency during adolescence. Developmental Neuropsychology, 6, 193-205.

Schooler, J. W., \& Loftus, E. (1986). Individual differences and experimentation: Complementary approaches to interrogative suggestibility. Social Behaviour, 1, 105-112.

Schultheiss, O. C., Dargel, A., \& Rohde, W. (2003). Implicit motives and sexual motivation and behavior. Journal of Research in Personality, 37, 224-230.

Scullin, M. H. \& Ceci, S. J. (2001). A suggestibility scale for children. Personality and Individual Differences, 30, 843-856.

Shapiro, L. R. (2004). Individual differences in children's suggestibility and source monitoring errors. Unpublished Manuscript, Emporia State University, Emporia, Kansas.

Singh, K. K. \& Gudjonsson, G. H. (1992). Interrogative suggestibility among adolescent boys and its relationship with intelligence, memory, and cognitive set. Journal of Adolescence, $15,155-161$.

Smith, P. \& Gudjonsson, G. H. (1995). Confabulation among forensic inpatients and its relationship with memory, suggestibility, compliance, anxiety, and self-esteem. Personality \& Individual Differences, 19, 517-523.

Tellegen, A. (1982). Brief manual for the Multidimensional Personality Questionnaire. Unpublished Manuscript, University of Minnesota, Minneapolis.

Thierry, K. L. \& Spence, M. J. (2002). Source-monitoring training facilitates preschoolers' eyewitness memory performance. Developmental Psychology, 38, 428-437.

Wilson, J. Q. \& Herrnstein, R. J. (1985). Crime and human nature. New York: Simon and Schuster. 
Table 1

Constructs and Measures

\begin{tabular}{ll}
\hline Construct & Measure \\
\hline Suggestibility & VSSA interview \\
Yield & \\
Shift & \\
Total Suggestibility & Free Recall portion of VSSA \\
Memory & Photo v. text test \\
Source monitoring ability & Unlikely virtues scale \\
Social desirability & Multidimensional Personality Questionnaire- Brief Form \\
Personality & \\
Constraint &
\end{tabular}


Table 2

Entire Sample: Descriptive Statistics

\begin{tabular}{|c|c|c|c|c|}
\hline Variable & $M$ & $S D$ & Min & $\operatorname{Max}$ \\
\hline Age & 17.92 & 2.73 & 13 & 23 \\
\hline Yield & 21.35 & 3.32 & 13 & 31 \\
\hline Shift & 10.59 & 6.03 & 0 & 46 \\
\hline Total Suggestibility & 31.94 & 7.09 & 15 & 62 \\
\hline Memory & 62.17 & 25.04 & 16 & 138 \\
\hline Source Monitoring & 16.77 & 3.48 & 5 & 26 \\
\hline Social Desirability & 2.93 & 2.03 & 0 & 9 \\
\hline Positive Emotionality & 33.89 & 7.96 & 6 & 48 \\
\hline Negative Emotionality & 15.30 & 7.79 & 0 & 39 \\
\hline Constraint & 21.62 & 4.91 & 8 & 33 \\
\hline Stress Reaction & 7.11 & 3.65 & 0 & 14 \\
\hline Alienation & 4.04 & 3.36 & 0 & 13 \\
\hline
\end{tabular}

Note. $N=200$. 
Table 3

Age Differences: Descriptive Statistics and Summary of Analyses of Variance

Variable $\quad M \quad S D \quad$ Min $\quad \operatorname{Max} F(1,199) \quad d \quad p$

Age

$\begin{array}{lllll}\text { Adolescents } & 15.44 & 1.04 & 13 & 17 \\ \text { Young Adults } & 20.56 & .79 & 19 & 23\end{array}$

Yield

$\begin{array}{llllllll}\text { Adolescents } & 22.73 & 3.08 & 15 & 31 & & & \\ \text { Young Adults } & 19.89 & 2.93 & 13 & 26 & & & \end{array}$

Shift

$\begin{array}{lccccccc}\text { Adolescents } & 11.30 & 6.35 & 1 & 46 & & & \\ \text { Young Adults } & 9.84 & 5.62 & 0 & 26 & & .00 & .086\end{array}$

Total Suggestibility

$\begin{array}{llllllll}\text { Adolescents } & 34.03 & 6.82 & 17 & 62 & & & \\ \text { Young Adults } & 29.72 & 6.72 & 15 & 51 & & .64 & .001\end{array}$

Memory

$\begin{array}{llllllll}\text { Adolescents } & 54.67 & 23.20 & 18 & 113 & & & \\ \text { Young Adults } & 70.13 & 24.57 & 16 & 138 & & .96 & .001\end{array}$

Source Monitoring

\begin{tabular}{|c|c|c|c|c|c|c|c|}
\hline Adolescents & 16.24 & 3.72 & 5 & 26 & & & \\
\hline & 17.32 & 3.14 & 8 & 25 & $4.86^{*}$ & .31 & .029 \\
\hline
\end{tabular}


Suggestibility 57

Social Desirability

$\begin{array}{llllllll}\text { Adolescents } & 3.46 & 2.07 & 0 & 9 & & & \\ \text { Young Adults } & 2.36 & 1.84 & 0 & 9 & & .56 & .001\end{array}$

Positive Emotionality

\begin{tabular}{|c|c|c|c|c|c|c|}
\hline Adolescents & 31.95 & 8.28 & 6 & 48 & & \\
\hline Young Adults & 35.95 & 7.09 & 16 & 48 & $13.3 \% *$ & .52 \\
\hline
\end{tabular}

Negative Emotionality

$\begin{array}{llllllll}\text { Adolescents } & 18.24 & 7.93 & 2 & 39 & & & \\ \text { Young Adults } & 12.17 & 6.31 & 0 & 31 & & .85 & .001\end{array}$

Constraint

\begin{tabular}{|c|c|c|c|c|c|c|}
\hline Adolescents & 20.89 & 5.10 & 8 & 33 & & \\
\hline Young Adults & 22.39 & 4.61 & 8 & 32 & $4.73^{*}$ & .31 \\
\hline
\end{tabular}

Stress Reaction

$\begin{array}{llllllll}\text { Adolescents } & 7.76 & 3.57 & 0 & 14 & & & \\ \text { Young Adults } & 6.42 & 3.62 & 0 & 14 & & .89 * & .001\end{array}$

Alienation

$\begin{array}{llllllll}\text { Adolescents } & 5.50 & 3.49 & 0 & 13 & & & \\ & & & & & 49.47^{*} & .99 & .001 \\ \text { Young Adults } & 2.50 & 2.41 & 0 & 10 & & & \end{array}$

Note. Adolescent $N=103$. Young Adult $N=97$.

$*_{p<.05}$ 
Table 4

Entire Sample: Correlations among Suggestibility and Contributor Variables

FR SM SocDes PE NE Con StressR Alien

$\begin{array}{ccccccccc}\text { Yield } & -.293 * * & -.127 & .179 * & -.069 & .201 * * & -.044 & .108 & .236^{* *} \\ \text { Shift } & -.268 * * & -.250 * * & .273 * * & -.134 & .102 & -.041 & .950 & .172 * \\ \text { TS } & -.365 * * & -.272 * * & .317 * * & -.146 * & .181 * & -.055 & .131 & .257 * *\end{array}$

Note. $\mathrm{TS}=$ Total suggestibility, $\mathrm{FR}=$ Free recall $($ Memory), $\mathrm{SM}=$ Source monitoring, SocDes $=$ Social desirability, $\mathrm{PE}=$ Positive emotionality, $\mathrm{NE}=$ Negative emotionality, $\mathrm{Con}=$ Constraint, StressR $=$ Stress reaction, Alien $=$ Alienation.

$N=200$.

$* p<.05 . * * p<.01$. 
Table 5

Correlations among Suggestibility and Contributor Variables by Age

FR SM SocDes PE NE Con StressR Alien

Yield

$\begin{array}{lllllllll}\text { Adolescents } & -.135 & -.044 & -.022 & .019 & .046 & .068 & .080 & .034 \\ \text { Young Adults } & -.242 * & -.099 & .193 & .078 & .033 & -.030 & -.018 & .091\end{array}$

Shift

$\begin{array}{lllllllll}\text { Adolescents } & -.389^{* *} & -.243^{*} & .221^{*} & -.081 & .010 & .014 & .022 & .108 \\ \text { Young Adults } & -.093 & -.225^{*} & .293^{* *} & -.144 & .136 & -.072 & .136 & .178\end{array}$

TS

\begin{tabular}{lllllllll} 
Adolescents & $-.414^{* *}$ & $-.246^{*}$ & $.196^{*}$ & -.067 & .030 & .044 & .057 & .116 \\
Young Adults & -.183 & $-.231^{*}$ & $.329 * *$ & -.086 & .128 & -.073 & .106 & .188 \\
& & & & & & & & \\
\hline
\end{tabular}

Note $. \mathrm{TS}=$ Total suggestibility, $\mathrm{FR}=$ Free recall $($ Memory), $\mathrm{SM}=$ Source monitoring, SocDes $=$ Social desirability, $\mathrm{PE}=$ Positive emotionality, $\mathrm{NE}=$ Negative emotionality, Con $=$ Constraint StressR $=$ Stress reaction, Alien $=$ Alienation

Adolescent $N=103$. Young Adult $N=97$.

${ }^{*} p<.05 .{ }^{* *} p<.01$. 
Table 6

Summary of Hierarchical Regression Analyses Contributing to Yield

Variable

$B \quad S E b \quad \beta$

Step 1

Age

$-2.84$

.43

$-.43 *$

Step 2

Age

$-2.48$

.44

$-.37 *$

Memory

$-.02$

.01

$-.18^{*}$

Step 3

Age

$-2.46$

.44

$-.37 *$

Memory

$-.02$

.01

$-.17 *$

Source Monitoring

$-.03$

.06

$-.03$

Step 4

Age

$-2.37$

.46

$-.36^{*}$

Memory

$-.02$

.01

$-.17 *$

Source Monitoring

$-.02$

.06

$-.03$

Social Desirability

.08

.11

.05

Step 5

Age

$-2.31$

.51

$-.35 *$

Memory

$-.02$

.01

$-.17 *$

Source Monitoring

$-.01$

.06

$-.01$ 
Social Desirability

Positive Emotionality

Negative Emotionality

Constraint

Step 6

Age

Memory

Source Monitoring

Social Desirability

Positive Emotionality

Negative Emotionality

Constraint

Age*Memory

Age*Source Monitoring

Age*Social Desirability
.11

.03

.02

.05

.50

$-.34^{*}$

.01

$-.18^{*}$

$-.03$

.06

$-.04$

.14

.11

.09

.03

.03

.08

.03

.03

.06

.03

.04

.01

.02

.004

.04

.01

.02

.03

$-.10$

.04

$-.16^{*}$

Note. $N=200$.

$R^{2}=.18$ for Step $1 ; \Delta R^{2}=.03$ for Step $2 ; \Delta R^{2}=.001$ for Step $3 ; \Delta R^{2}=.003$ for Step $4 ; \Delta R^{2}=$ .006 for Step 5; $\Delta R^{2}=.03$ for Step 6; Full Model $R^{2}=.25$.

$* p<.05$. 


\section{Table 7}

Summary of Hierarchical Regression Analyses Contributing to Shift

Variable

$B \quad S E b \quad \beta$

Step 1

Age

$-1.47$

.85

$-.12$

Step 2

Age

$-.52$

.87

$-.04$

Memory

$-.06$

.02

$-.26^{*}$

Step 3

Age

$-.28$

.86

$-.02$

Memory

$-.05$

.02

$-.22 *$

Source Monitoring

$-.35$

.12

$-.20 *$

Step 4

Age

.36

.86

.03

Memory

$-.05$

.02

$-.21 *$

Source Monitoring

$-.30$

.12

$-.17 *$

Social Desirability

.66

.20

$.22 *$

Step 5

Age

1.08

.95

.09

Memory

$-.05$

.02

$-.19 *$

Source Monitoring

$-.30$

.12

$-.17^{*}$ 


$\begin{array}{lccc}\text { Social Desirability } & .74 & .21 & .25^{*} \\ \text { Positive Emotionality } & -.07 & .05 & -.09 \\ \text { Negative Emotionality } & .06 & .06 & .08 \\ \text { Constraint } & -.04 & .08 & -.04\end{array}$

Step 6

\begin{tabular}{lccc} 
Age & 1.24 & .95 & .10 \\
Memory & -.05 & .02 & $-.21^{*}$ \\
Source Monitoring & -.31 & .12 & $-.18^{*}$ \\
Social Desirability & .76 & .21 & $.26^{*}$ \\
Positive Emotionality & -.05 & .05 & -.07 \\
Negative Emotionality & .06 & .06 & .08 \\
Constraint & -.05 & .08 & -.04 \\
Age*Memory & -.02 & .01 & $-.17^{*}$ \\
Age*Source Monitoring & .02 & .05 & .03 \\
Age*Social Desirability & -.08 & .08 & -.07 \\
\hline
\end{tabular}

Note. $N=200$.

$R^{2}=.02$ for Step $1 ; \Delta R^{2}=.06$ for Step $2 ; \Delta R^{2}=.04$ for Step $3 ; \Delta R^{2}=.05$ for Step $4 ; \Delta R^{2}=.02$ for Step 5; $\Delta R^{2}=.03$ for Step 6; Full Model $R^{2}=.20$. $* p<.05$. 
Table 8

Summary of Hierarchical Regression Analyses Contributing to Total Suggestibility

Variable

$B \quad S E b \quad \beta$

Step 1

Age

$-4.31$

.96

$-.30 *$

Step 2

Age

$-3.00$

.96

$-.21 *$

Memory

$-.08$

.02

$-.30 *$

Step 3

Age

$-2.73$

.10

$-.19 *$

Memory

$-.08$

.02

$-.27 *$

Source Monitoring

$-.38$

.13

$-.19 *$

Step 4

$\begin{array}{lccc}\text { Age } & -2.01 & .95 & -.14^{*} \\ \text { Memory } & -.07 & .02 & -.26^{*} \\ \text { Source Monitoring } & -.33 & .13 & -.16^{*} \\ \text { Social Desirability } & .75 & .23 & .22^{*}\end{array}$

Step 5

Age

$-1.23$

1.06

$-.09$

Memory

$-.07$

.02

$-.25 *$

Source Monitoring

$-.31$

.13

$-.15^{*}$ 
Social Desirability

Positive Emotionality

Negative Emotionality

Constraint

Step 6

Age

Memory

Source Monitoring

Social Desirability

Positive Emotionality

Negative Emotionality

Constraint

Age*Memory

Age*Source Monitoring

Age*Social Desirability
.85

$-.04$

.09

$-.04$

$-1.00$

1.05

$-.07$

$-.07$

$-.34$

.90

$-.02$

.09

$-.05$

$-.01$

3.43

$-.18$
.24

.06

.07

.09

$-.03$

.10
$.02-.26 *$

.13

$-.17 *$

.24

$.26^{*}$

.06

$-.03$

.10

$-.03$

$-.13 *$

.04

$-.13 *$

Note. $N=200$.

$R^{2}=.09$ for Step $1 ; \Delta R^{2}=.08$ for Step $2 ; \Delta R^{2}=.03$ for Step $3 ; \Delta R^{2}=.04$ for Step $4 ; \Delta R^{2}=.01$ for Step 5; $\Delta R^{2}=.03$ for Step 6; Full Model $R^{2}=.29$.

$* p<.05$ 


\section{Appendix A}

\section{Personality Inventory}

Instructions: In this booklet, you will find a series of statements someone might use to describe his or her opinions, interests, experiences, or other characteristics.

For most of the statements, simply decide whether each is true for you, and then record your answer on the answer sheet, by marking "t" (True) or " $\mathrm{f}$ " (False). For some of the statements, instead of having to say whether they are true or false, you are presented with two choices, one labeled ( $\mathrm{t}$ ) and the other labeled (f). Choose the one that you think provides the best answer, and then mark the corresponding letter ( $t$ or $f)$ on your answer sheet.

Read the statements carefully but try not to spend too much on each one. Answer every statement, even if you are not completely sure about your answer. Record answers on the answer sheet in pencil.

1. At times I have been envious of someone.

2. I am quite effective at persuading people to do things.

3. Some people say that I put my work ahead of too many other things.

4. I have occasionally felt discouraged about something.

5. I usually like to spend my leisure time with friends rather than alone.

6. Often I get irritated at little annoyances.

7. Many people try and push me around.

8 . When I get angry I am often ready to hit someone.

9. I like to stop and think things over before I do them.

10. I am often nervous for no reason.

11. I might enjoy riding in an open elevator to the top of a tall building under construction.

12. I don't like to see religious authority overturned by so-called progress and logical reasoning.

13. I can be deeply moved by a sunset.

14. My table manners are not always perfect.

15. I enjoy being in the spotlight.

16. I set extremely high standards for myself in my work.

17. When I am unhappy about something,

(t) I tend to seek the company of a friend.

(f) I prefer to be alone.

18. I am not at all sorry to see many of the traditional values change.

19. I know that certain people would enjoy it if I got hurt.

20. When someone hurts me, I tend to retaliate (get even).

21. I am more likely to be fast and careless than to be slow and plodding.

22. It might be fun and exciting to experience an earthquake.

23. Strict discipline in the home would prevent much of the crime in our society.

24. When listening to organ music or other powerful music, I sometimes feel as if am being lifted into the air.

25. I have always been extremely courageous in facing difficult situations.

26. I often feel happy and satisfied for no particular reason.

27. I often keep working on a problem even if I am very tired. 
28. I am usually happier when I am alone.

29. I suffer from nervousness.

30. People often try to take advantage of me.

31. Basically I am a happy person.

32. I admit that I sometimes take pleasure in hurting someone physically.

33. I often prefer to "play things by ear" rather than to plan ahead.

34. Of the following two situations I would like least:

(t) Having a pilot announce that the plane has engine trouble and he may have to make an emergency landing.

(f) Working in the fields digging potatoes.

35. The best way to achieve a peaceful world is to improve people's morals.

36. Sometimes thoughts and images come to me without the slightest effort on my part.

37. At times I have been envious of someone.

38. I live a very interesting life.

39. People consider me forceful.

40. I am a warm person rather than cool and detached.

41. I often find myself worrying about something.

42. People often say mean things about me.

43. I see no objection to stepping on people's toes a little if it is to my advantage.

44. When faced with a decision I usually take the time to consider and weigh all aspects.

45. I usually do not like to be a "follower".

46. I would enjoy trying to cross the ocean in a small but seaworthy sailboat.

47. More censorship of books and movies is a violation of free speech and should be abolished.

48. If I wish, I can imagine (or daydream) some things so vividly that they hold my attention as a good movie or story does.

49. My opinions are always completely reasonable.

50. Every day I do some things that are fun.

51. When I work with others, I like to take charge.

52. People say I drive myself hard.

53. I am too sensitive for my own good.

54. My "friends" have often betrayed me.

55. I enjoy a good brawl.

56. I am very level-headed and always like to keep my feet on the ground.

57. Of the following two situations I would like least:

(t) Having to walk around all day on a blistered foot.

(f) Sleeping out on a camping trip in an area where there are rattlesnakes.

58. It is a pretty callous (unfeeling) person who does not fell love and gratitude toward her/his parents.

59. Sometimes I can change noise into music by the way I listen to it.

60. If I have a humiliating experience I get over it very quickly.

61. I have at times eaten too much.

62. I usually find ways to liven up my day.

63. On most social occasions I like to have someone else take the lead.

64. I am not terribly ambitious.

65. I am more of a "loner" than most people. 
66. I would be more successful if people did not make things difficult for me.

67. Sometimes I hit people who have done something to deserve it.

68. I almost never do anything reckless.

69. Of the following two situations I would like least:

(t) Being out on a sailboat during a great storm at sea.

(f) Having to stay home every night for two weeks with a sick relative.

70. I would prefer to see:

(t) Stricter observance of the Sabbath.

(f) Greater freedom in regard to divorce.

71. I can often somehow sense the presence of another person before I actually see or hear him / her.

72. I have always been completely fair to others.

73. People rarely try to take advantage of me.

74. Most mornings the day ahead looks bright to me.

75. I am very good at influencing people.

76. I enjoy putting in long hours.

77. For me one of the most satisfying experiences is the warm feeling of being in a group of good friends.

78. Occasionally I experience strong emotions - anxiety, anger - without really knowing what causes them.

79. I would rather turn the other cheek than get even when someone treats me badly.

80. I often act on the spur of the moment.

81. Of the following two situations I would like least:

(t) Being at the circus when two lions suddenly get loose down in the ring.

(f) Bringing my whole family to the circus and then not being able to get in because a clerk sold me tickets for the wrong night.

82. Higher standards of conduct are what this country needs most.

83. The sound of a voice can be so fascinating to me that I can just go on listening to it.

84. I have at times been angry with someone.

85. Most days I have moments of real fun or joy.

86. I often act without thinking.

87. When it is time to make decisions, other usually turn to me.

88. I often go on working on a problem long after others would have given up.

89. I prefer to work alone.

90. Minor setbacks sometimes irritate me too much.

91. People often just use me instead of treating me as a person.

92. I don't like to start a project until I know exactly how to proceed.

93. Of the following two situations I would like least:

(t) Riding along a stretch of rapids in a canoe.

(f) Waiting for someone who is late.

94. I am disgusted by foul language.

95. Some music reminds me of pictures or changing color patterns.

96. I always tell the entire truth.

97. I often feel sort of lucky for no special reason.

98. I do no like to be the center of attention on social occasions.

99. I work just hard enough to get by without overdoing it. 
100. I have few or no close friends.

101. I sometimes get myself into a state of tension and turmoil as I think of the day's events. 102. Some people oppose me for no good reason.

103. I can't help but enjoy it when someone I dislike makes a fool of himself / herself.

104. I seldom feel really happy.

105. Of the following two situations I would like least:

(t) Being chosen as the "target" for a knife-throwing act.

(f) Being sick to my stomach for 24 hours

106. No decent person could ever think of hurting a close friend or relative.

107. I am able to wander off into my on thoughts while doing a routine task and actually forget that I am doing the task, and then I find a few minutes later that I have completed it.

108. Sometimes I'm a bit lazy.

109. Every day interesting and exciting things happen to me.

110. I am quite good at convincing other to see things my way.

111. I push myself to my limits.

112. I am happiest when I see people most of the time.

113. I am often troubled by guilt feelings.

114. I know that people have purposely spread false rumors about me.

115. I like to watch a good, vicious fight.

116. Before I get into a new situation I like to find out what to expect from it.

117. I perform for an audience whenever I can.

118. I am not at all sorry to see many of the traditional values change.

119. I can sometimes recollect certain past experiences in my like with such clarity and vividness that it is like living them again or almost so.

120. Never in my whole life have I taken advantage of anyone.

121. In my spare time I usually find something interesting to do.

122. On social occasions I usually allow others to dominate the conversation.

123. I like to try difficult things.

124. I prefer not to "open up" too much, even to friends.

125. I sometimes change from happy to sad, or vice versa, without good reason.

126. I have often been lied to.

127. Sometimes I just like to hit someone.

128. I am a cautious person.

129. Of the following two situations I would like least:

(t) Being in a flood.

(f) Carrying a ton of coal from the backyard into the basement.

130. At times I somehow feel the presence of someone who is not physically there.

131. I have sometimes felt slightly hesitant about helping someone who asked me to.

132. My feelings are hurt rather easily.

133. For me life is a great adventure.

134. I do not like to organize other people's activities.

135. I find it really hard to give up on a project when it proves too difficult.

136. I often prefer not to have people around me.

137. I often lose sleep over my worries.

138. When people are friendly they usually want something from me. 
139. When people insult me, I try to get even.

140. I usually make up my mind through careful reasoning.

141. Of the following two situations I would like least:

(t) Being seasick every day for a week while on an ocean voyage.

(f) Having to stand on the ledge of the $35^{\text {th }}$ floor of a hotel because there's a fire in my room.

142. People should observe moral laws more strictly than they do.

143. I have never felt that I was better than someone else.

144. I always seem to have something pleasant to look forward to.

145. I don't enjoy truing to convince people of something.

146. I like hard work.

147. Never in my whole life have I wished for anything that I was not entitled to.

148. I am rather aloof and maintain distance between others and myself.

149. There are days when I'm "on edge" all of the time.

150. I have had a lot of bad luck.

151. Sometimes I seem to enjoy hurting someone by saying something mean.

152. I generally do not like to have a detailed plan.

153. It might be fun learning to walk a tightrope.

154. High moral standards are the most important thing parents can teach their children.

155. It is sometimes possible for me to be completely immersed in nature or in art and tend to feel as if my whole state of consciousness has somehow been temporarily altered. 


\section{Appendix B}

\section{Demographics Questionnaire}

1. What is your gender?

male

female

2. Age?

month of birth

year of birth

3. What is your class rank?

freshman
sophomore
junior
senior

4. What is your overall GPA?

5. How would you rate your overall memory ability?

much better than average somewhat better than average average somewhat below average much below average

6. Are you color blind?

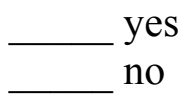

7. Do you require corrective eyewear (glasses, contacts, etc.)?

$\underset{\text { nes }}{\text { no }}$

8. If you answered yes to number 8 are you wearing your corrective eyewear?

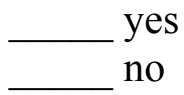


9. How would you rate the quality of your eyesight?

much better than average somewhat better than average average somewhat below average much below average 


\section{Appendix C}

The Video Suggestibility Scale for Adults Interview

Five to eight days after the individual has seen the video:

\section{Open-ended questions}

A. Do you remember the video about the carjacking? Tell me everything you remember about the carjacking, even the thing you think aren't important.

Repeatedly probe: What else do you remember?

When the individual finishes responding, ask?

B. Who was at the carjacking? For each character from the list of characters that the individual generates AND for any characters mentioned above in the open-ended questioning, ask the following two questions:

B1a. What did look like?

B1b. What was he/she wearing?

B2a. What did

B2b. What was he/she wearing?

B3a. What did look like?

$\mathrm{B} 3 \mathrm{~b}$. What was he/she wearing?

C. Continue asking about characters generated by the individual and conclude by asking: Who else was at the carjacking?

C1a. What did look like?

C1b. What was he/she wearing?

C2a. What did look like?

$\mathrm{C} 2 \mathrm{~b}$. What was he/she wearing? 


\section{Open-ended questions}

D. Do you remember the video about the burglary? Tell me everything you remember about the burglary, even the thing you think aren't important.

Repeatedly probe: What else do you remember?

When the individual finishes responding, ask?

E. Who was at the burglary? For each character from the list of characters that the individual generates AND for any characters mentioned above in the open-ended questioning, ask the following two questions:

E1a. What did look like?

E1b. What was he/she wearing?

E2a. What did

E2b. What was he/she wearing? look like?

E3a. What did look like?

E3b. What was he/she wearing?

F. Continue asking about characters generated by the individual and conclude by asking: Who else was at the burglary?

F1a. What did look like?

F1b. What was he/she wearing?

F2a. What did look like?

F2b. What was he/she wearing? 
G. Probe questions

1. Was the perpetrator wearing a baseball hat?

2. Was the perpetrator wearing a dark blue sweatshirt?

3. Was the cameraman tall?

4. Was the cameraman bald?

5. Did the cameraman have brown hair?

6. Was the perpetrator bald?

7. Was the victim wearing shorts?

8. Was the victim blonde?

9. Was the victim wearing a green shirt?

10 . Was the victim wearing glasses?

11. Did the perpetrator have a knife?

12 . Were there any witnesses?

13. Did the event take place at night or during the day?

14 . Was the victim's vehicle black?

15 . Was there a highway nearby?

16 . Were there houses nearby?

17. Was the victim's car the only one in the parking lot?

18. Were there two perpetrators?

19. Was the camera that the perpetrators used stolen?

20 . Were the perpetrators in a parking lot?

21. Was it the cameraman's idea to steal a car?

22. Were the perpetrators admiring the car before they saw the woman?

23. Were the perpetrators waiting for the girl to leave the store?

24. Was the woman leaving a CVS store?

25 . Was the victim carrying one or two bags?

26. Did the perpetrator leave behind the knife?

27. Was the victim talking on her cell phone?

28. Did the victim speak to the perpetrators?

29. Did the victim drop her purse?

30. Did the victim scream for help?

31. Did the victim attempt to use her mace?

32. Did the victim's friend run away?

33. Did the victim run toward her vehicle?

34. Did you hear the baseball bat hit the victim's head?

35. Did the bat get bloody?

36 . Did the perpetrator kick the victim when she was on the ground?

37. Did the perpetrator drop the bat he used on the victim?

38. Did the victim's shoes fall off when she fell to the ground?

39. Did the victim tear her dress?

40. Did the perpetrator stab the victim?

41. Did the perpetrators hit the girl with the car?

42. Did the perpetrator hotwire the car?

43. Did the perpetrators steal the victim's purse?

44. Did the perpetrators steal the victim's wallet? 
45. Was the victim coherent and moving when the perpetrators fled the scene?

46. Did the perpetrator take her necklace?

47. Was the knife left at the crime scene?

48. Did the perpetrators run into an alley?

49. Were you able to hear sirens in the background?

50. Did the perpetrators leave the purse behind after they abandoned the car?

51 . Were the perpetrators laughing about the crime?

H. Probe questions

1. Did one of the burglars have curly hair?

2. Did one of the burglars have a goatee?

3. Did one of the burglars have glasses?

4. Did the cameraman have a black shirt on?

5. Was the girl wearing a skirt?

6. Did the little girl have black hair?

7. Did the man with the curly hair have glasses?

8. Were the neighbors at home?

9. Did one of the burglars smoke?

10. Was the burglar with glasses wearing a white or blue shirt?

11. Was one of the burglars wearing a hat and glasses?

12. Did the cameraman break into the house once before?

13. Did the burglars enter into the kitchen of the house?

14. Did the burglars take two beers out of the refrigerator?

15. Did the burglars turn off the burglar alarm?

16. Was the computer turned on?

17. Were the burglars drinking beer while robbing the house?

18. Did one of the burglars have a fear of dogs?

19 . Were the homeowners not home because they were on vacation?

20 . Were the neighbors at the movies that night?

21. Did they steal video games?

22. Did they steal a gold watch?

23. Did they steal a bass guitar?

24. Did they steal some jewelry?

25. Did they get the guitar they wanted?

26. Did the burglar use water or beer to extinguish the small fire he started with his cigarette?

27. Did they take movies or video games?

28. How much money did the burglars steal from the house?

29. Did the burglars hear police sirens?

30. Did the burglars exit through a window?

31. Did you see the burglar place the Palm Pilot into his pocket?

32. Were the burglars going to sell the watch or the ring for beer money?

33 . Were you able to hear traffic in the background?

34 . Were the burglars concerned about the traffic?

35. Did one of the burglars trip and fall when he was going upstairs?

36 . Were the lights on in the living room when they first entered the house? 
37. Did the burglars track muddy footprints onto the kitchen floor?

38. Did you see the burglar put the jewelry box into his pocket?

39. Were the burglars startled when they heard the knock on the door?

40. Did one of the burglars previously cut the screen in order to gain entry?

41. Were the burglars armed with guns?

42. Was the dog outside on its runner?

43. Did the owners of the house yell at the burglars as they were leaving?

44. Did the burglars steal the car keys?

45. Did one of the burglars check his email?

46. Did they steal the computer?

47. Did they climb through the window?

48. Did the burglars steal money out of the wallet?

49. Did they steal the TV so they could play the video games?

50. Did the take the Play Station?

51. Was one of the burglars bleeding after he fell down the stairs on the way out?

52. Did the little girl wear glasses?

53. Did the little girl call the police?

54. Did the little girl yell for her mom when she caught the perpetrators?

55. Did all of the burglars escape the scene safely?

56. Did the burglars leave anything behind at the scene?

57. Did the burglars use a black car as their getaway vehicle?

58 . Were the burglars playing the video games they stole?

59. Did they decide to rob another house?

60. Did the cameraman say that he would make copies of the tape for the other burglars? 


\section{Appendix D}

\section{Source Monitoring Measure}

\section{$\underline{\text { Pictorial }} \underline{\text { Scene }} \underline{\text { Interpretation }}$}

Please describe the general nature of the scene depicted in the slide. Use one or two simple sentences to identify the basic subject of the picture. 


\section{Crime Stoppers}

"Crime Stoppers" is an organization that offers monetary rewards for information concerning crimes. Although they are usually fairly small, Crime Stoppers' offices are busy and intense places. Earlier, you were shown a picture of a Crime Stoppers office. The following is a description of that picture.

There are two men and two women in the room. The two men are seated, and both are holding telephone receivers. The two women are standing in the background to the right. The man in the foreground is wearing a pinstripe suit with a solid burgundy tie. He is looking into the camera with a very stern look on his face, and is holding a telephone receiver in his left hand. He is seated in front of a desk that is cluttered with objects such as a telephone and a yellow writing pad. There is also a small stand-up desk calendar on the desk, as well as lots of papers and other things. The man in the background (over to the left of the picture) is dressed in a grey suit. He has dark hair. He's sitting at a desk, talking on a telephone. There are some shelves on the wall directly behind him. These shelves run the length of the back wall. There is an open file folder on the desk in front of him. The base of the telephone is also on the desk, but it is not in the picture. Standing a few yards to his left (that is, on the right side of the picture), are two women who appear to be engaged in conversation. The woman closer to the center of the picture is wearing a police uniform. Behind them, against the back wall are the shelves. There are a number of door locks, door knobs, and various kinds of hinges on the shelves - probably highsecurity locks and related gadgets. The woman in uniform is holding some pamphlets in her right hand. The women are standing almost directly behind the man in the foreground, who is sitting in a reddish-orange desk chair. The floor is grey carpet or tile. The ceiling is not pictured. Overall, the picture suggests a rather hectic atmosphere. 


\section{$\underline{\text { Textual Scene Description }}$}

Please describe the general nature of the scene depicted in the text. Use one or two simple sentences to identify the basic subject of the text. 


\section{Crime Stoppers Memory Test}

We want to know whether or not people notice and remember the same kinds of details in pictures as they do in texts. To get at this question, we need to know which of your memories of the Crime Stoppers office were derived from the picture and which were derived from the text.

For each of the items on the following pages, please indicate the source (or sources) of your memory of that item by checking the box in the appropriate column: Both, if you remember noticing the item both in the picture and in the text; Picture, if you remember noticing the item in the picture but not in the text; Text, if you remember noticing the item in the text but not in the picture; None, if you do not remember noticing the items in either source.

As you make each answer, please rate how confident you are about the source of that memory by placing a check in the appropriate column: GUESS, if you are just guessing; MED, if you are medium-sure that your answer is correct; or HIGH, if you are highly confident that your answer is correct.

Answer every item, even if you have to guess. Do the items one at $\underline{\text { a time }} \underline{\text { in }} \underline{\text { the order }}$ given. Do not change any of your answers. Move through the test fairly quickly; don't be careless, but don't agonize over each answer.

\section{If you are not completely clear on the instructions, please read them again!}




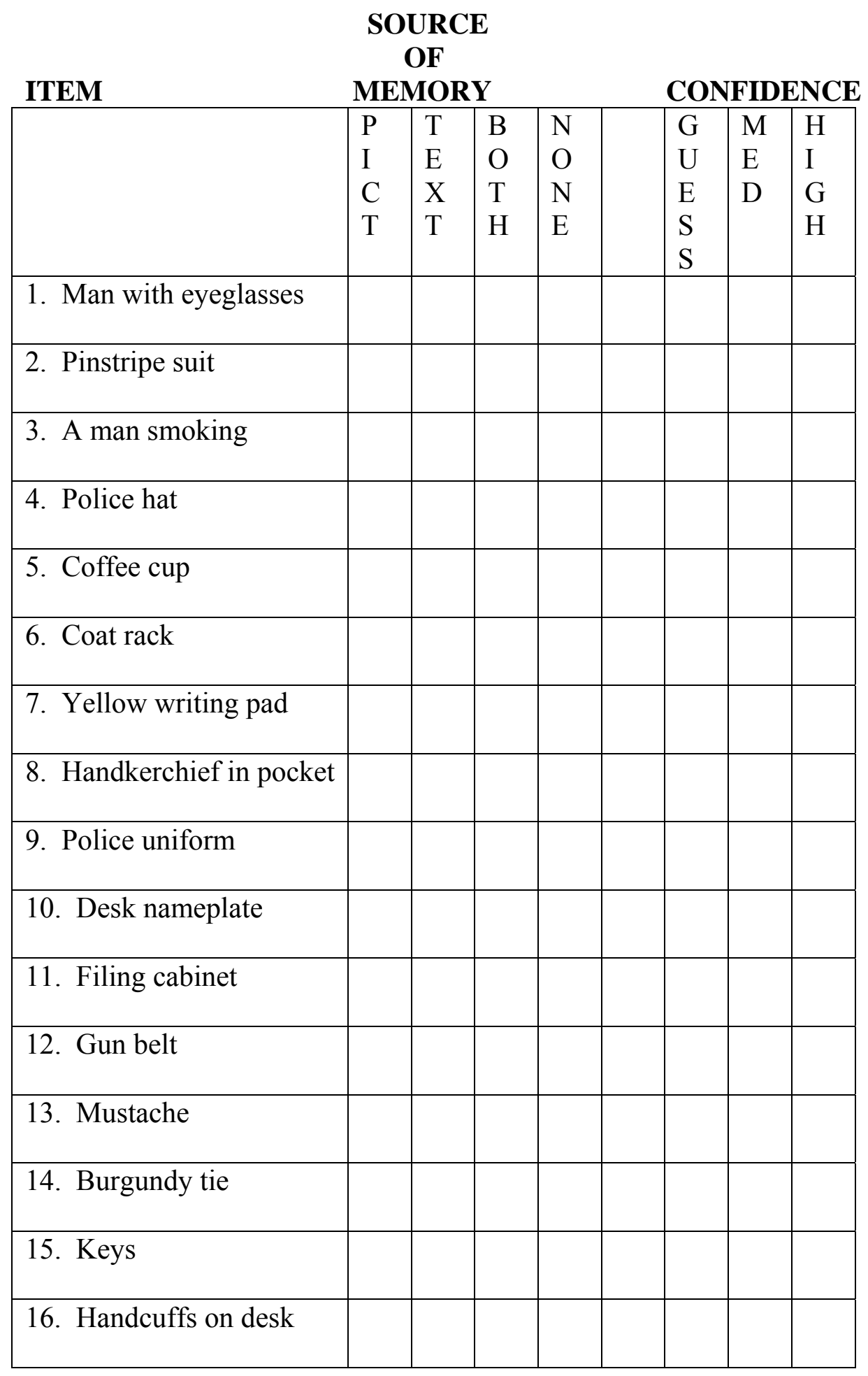




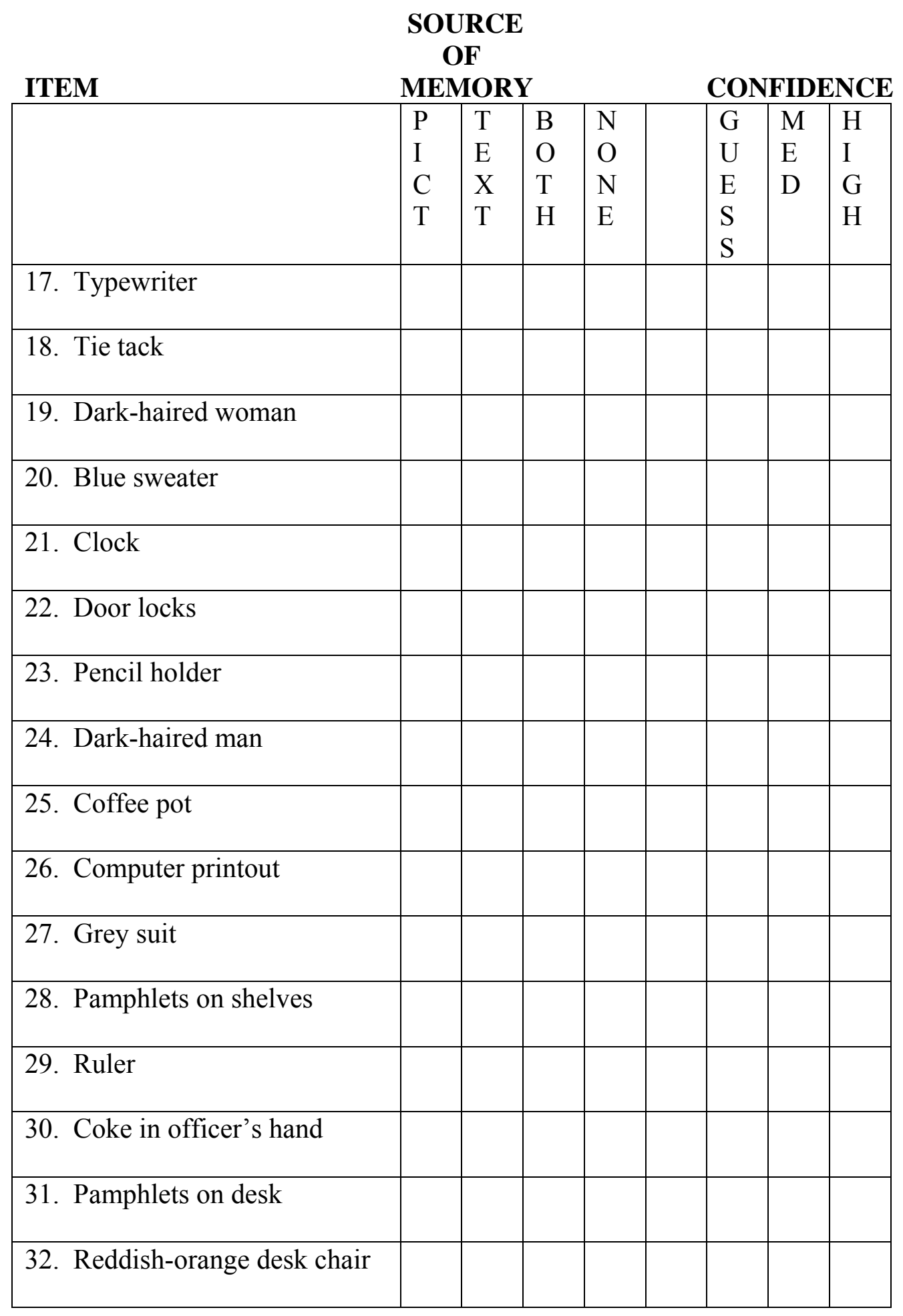




\section{Appendix E}

Unlikely Virtues Scale of the Multidimensional Personality Questionnaire

1. My table manners are not always perfect.

2. I have always been extremely courageous in facing difficult situations.

3. At times I have been envious of someone.

4. My opinions are always completely reasonable.

5. I have at times eaten too much.

6. I have always been completely fair to others.

7. I have at times been angry with someone.

8. I always tell the entire truth.

9. Sometimes I'm a bit lazy.

10. Never in my whole life have I taken advantage of anyone.

11. I have sometimes felt slightly hesitant about helping someone who asked me to.

12. I have never felt that I was better than someone else.

13. I have occasionally felt discouraged about something.

14. Never in my whole life have I wished for anything that I was not entitled to. 